\title{
Properties and medical applications of polylactic acid:
} \section{A review}

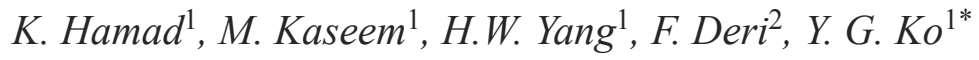 \\ ${ }^{1}$ Plasticity Control \& Mechanical Modeling Laboratory, School of Materials Science \& Engineering, Yeungnam \\ University, Gyeongsan 712-749, South Korea \\ ${ }^{2}$ Laboratory of Materials Rheology, Department of Chemistry, University of Damascus, Damascus, Syria
}

Received 30 September 2014; accepted in revised form 30 November 2014

\begin{abstract}
Polylactic acid (PLA), one of the well-known biodegradable polyesters, has been studied extensively for tissue engineering and drug delivery systems, and it was also used widely in human medicine. A new method to synthesize PLA (ring-opening polymerization), which allowed the economical production of a high molecular weight PLA polymer, broadened its applications, and this processing would be a potential substitute for petroleum-based products. This review described the principles of the polymerization reactions of PLA and, then, outlined the various materials properties affecting the performance of PLA polymer, such as rheological, mechanical, thermal, and barrier properties as well as the processing technologies which were used to fabricate products based on PLA. In addition, the biodegradation processes of products which were shaped from PLA were discussed and reviewed. The potential applications of PLA in the medical fields, such as tissue engineering, wound management, drugs delivery, and orthopedic devices, were also highlighted.
\end{abstract}

Keywords: biodegradable polymers, polylactic acid, properties, medical applications

\section{Introduction}

In recent years, considerable research effort has been devoted to the use of polymeric biodegradable materials in plastics applications, such as packaging, to reduce the environmental impact related to the accumulation of plastics waste from the day-to-day applications of plastic materials based on traditional polymers, such as polyethylene terephthalate (PET), polyethylene (PE), etc. $[1,2]$. One of the promising polymers used in these applications was the polylactic acid (PLA), which was an aliphatic polyester derived from lactic acid (2-hydroxypropionic acid) [3].

First, PLA with a low-molecular weight was synthesized by Carothers in 1932 [4, 5]. Further work by DuPont resulted in a higher-molecular weight product patented in 1954 [6]. Accordingly, two methods were used to produce the basic block of PLA, lactic acid (LA): the chemical synthesis was based on petrochemical feedstock and carbohydrate fermentation (Figure 1). Although the former was more familiar to chemists, the fermentation of natural materials containing carbohydrates, such as rice, corn, etc., was the main method used to produce LA $(>90 \%)$. Datta and Henry [7] examined the synthesis and purification technologies of LA that were found in two enantiomers, L- and D-lactic acid. The results reported in that work showed that a 50/50 optically inactive mixture of $\mathrm{L}$ and $\mathrm{D}$ could be produced via a chemical route. In contrast, fermentation-derived lactic acid existed almost exclusively as L-lactic acid. The ability to produce the L-isomer in high purity possessed important ramifications in chemistry and the ultimate process/property relationships achievable in the polymers produced from lactic acid.

\footnotetext{
${ }^{*}$ Corresponding author, e-mail: younggun@ynu.ac.kr (C) BME-PT
} 


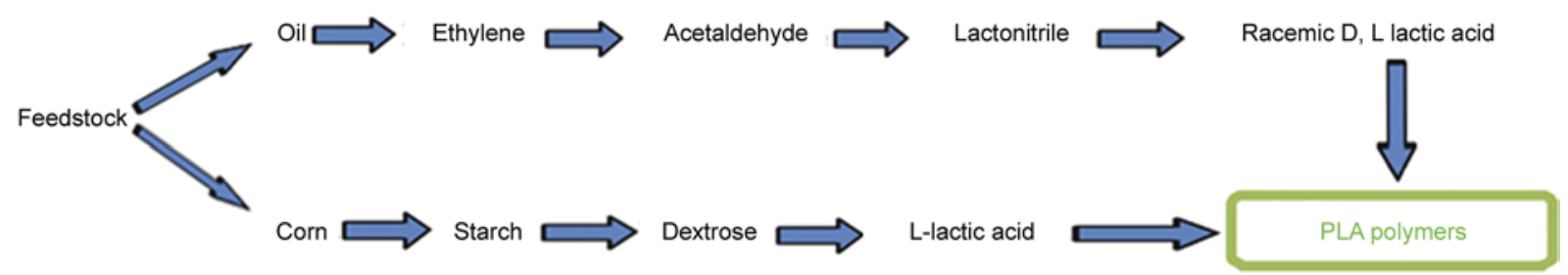

Figure 1. Lactic acid preparation methods

Biodegradable polymers attracted considerable attention in medical applications because they exhibited advantages over the non-biodegradable polymers, including an elimination of the need to remove implants and biocompatibility. Recently, PLA and its systems played an effective role in medical applications, where the use of PLA in these applications was not based solely on its biodegradability because it was made from renewable resources, but PLA was being used because it worked very well and provided the excellent properties at a low cost as compared to other traditional biodegradable polymers used in medical applications. A range of devices were prepared from different PLA types, including degradable sutures, drug releasing micro-particles, nano-particles, and porous scaffolds for cellular applications [8]. In addition, the excellent properties of PLA, including mechanical properties, thermal properties, barrier properties, and processability, using traditional processing technologies, such as extrusion, injection molding, compression molding, and blow molding, broadened its applications. The aim of this review paper is to discuss the properties for PLA and summarizes the medical applications of PLA.

\section{Synthesis of polylactic acid}

LA monomers synthesized using the last two methods as shown in Figure 1 were converted to PLA polymers using a range of polymerization processes, including polycondensation, ring opening polymerization and azeotopic dehydration condensation reaction (Figure 2).

Although polycondensation (PC) including solution polycondensation and melt polycondensation was the least expensive route, it was difficult to obtain a solvent-free high molecular weight PLA using these routes. In solution methods, commercial LA aqueous solution was distilled under reduced pressures and high temperatures, and the product of the distillation process was then mixed with the catalyst and solvent, and charged to a reactor under heating. The byproduct (water) was continually removed azeotropically, and the resulting polymer (PLA) was dissolved in the solvent and precipitated twice in excess methanol. Tin (II) chloride was the most commonly used catalyst and could be recovered at the end of the reaction. Because the polymer in this reaction was a low to intermediate molecular weight material, the coupling agents, such as isocyantes, epoxides or per-
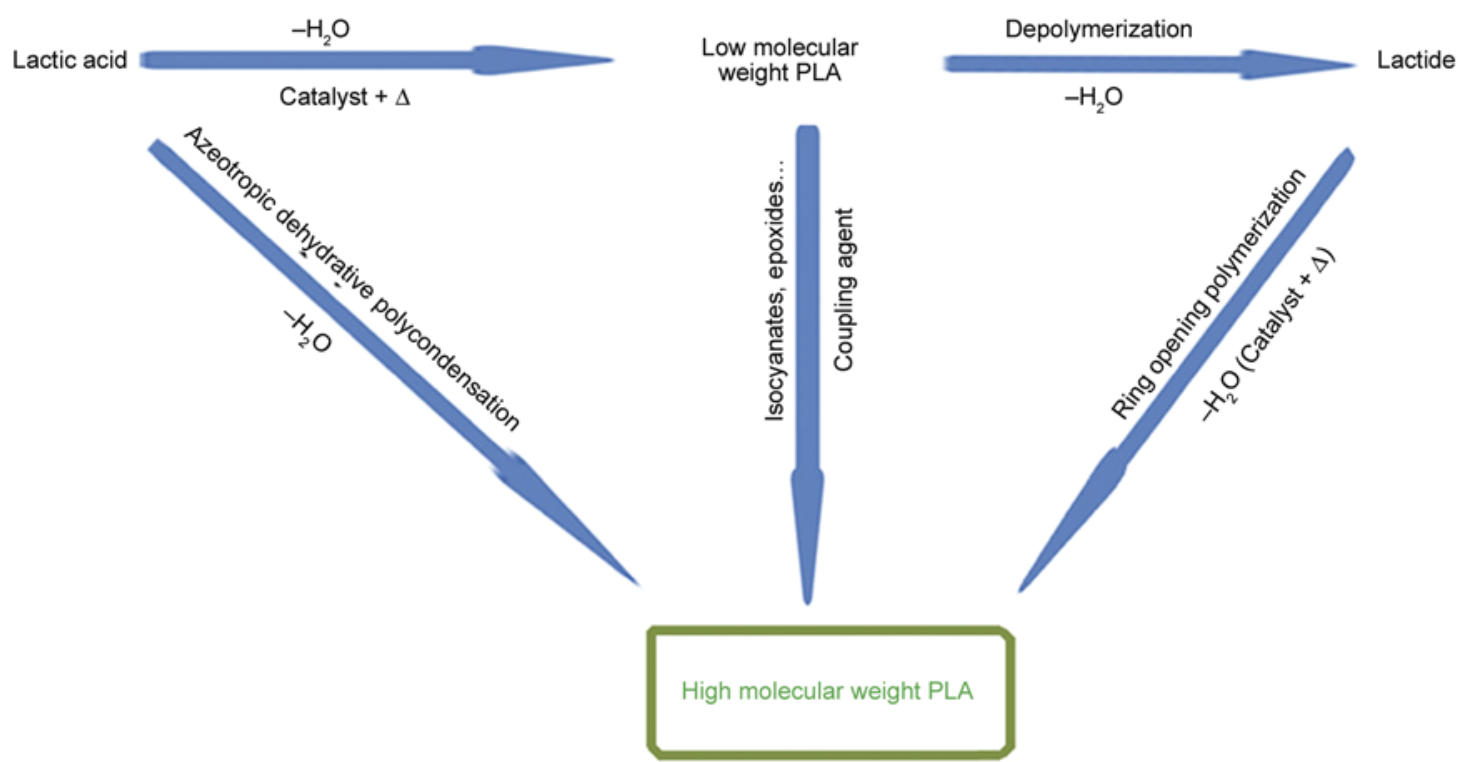

Figure 2. PLA preparation technologies 
oxides, could be incorporated to produce a range of molecular weights. In contrast, the azeotropic dehydration condensation reaction of LA was a method used to yield high molecular weight PLA without the use of chain extenders or adjuvants.

In general, low molecular weights PLA polymers (no more than $30 \mathrm{kDa}$ [9]) were produced using this process, and several studies reported an increase in the molecular weight of PLA polymers using the PC method. Zei et al. [10] used an aqueous solution of LA to prepare PLA in the presence of two catalysts (tin (II) chloride and succinic anhydride), and they reported a molecular weight in $\mathrm{kDa}$ region. Achmad et al. [11] fabricated higher molecular weights of PLA polymers where LA was polymerized by direct PC under controlled temperatures and pressures without catalyst, solvent or initiators. The effects of the reaction temperature and pressure on the resulting molecular weights were examined. The results showed that high molecular weights of $90 \mathrm{kDa}$ could be obtained at $200^{\circ} \mathrm{C}$ after $\sim 90 \mathrm{~h}$ under vacuum condition (Figure 3 ). In addition, the Mitsui Toatsu chemical company used organic solvents with a high boiling point to prepare poly-DL-lactic acid (PDLLA) by direct solution PC, in which the lactic acid, catalysts, and solvents were mixed in a reactor so as to produce high molecular weights of approximately $300 \mathrm{kDa}$ [12].

On the other hand, ring-opening polymerization (ROP), which occurred by ring opening of the lactide (cyclic dimmer of lactic acid) in the presence of a catalyst, was the most commonly used method to obtain high molecular weight PLA [13]. This method consisted of three steps: polycondensation of LA monomers to low-molecular weight PLA, depolymerization of the PLA into the lactide, and catalytic

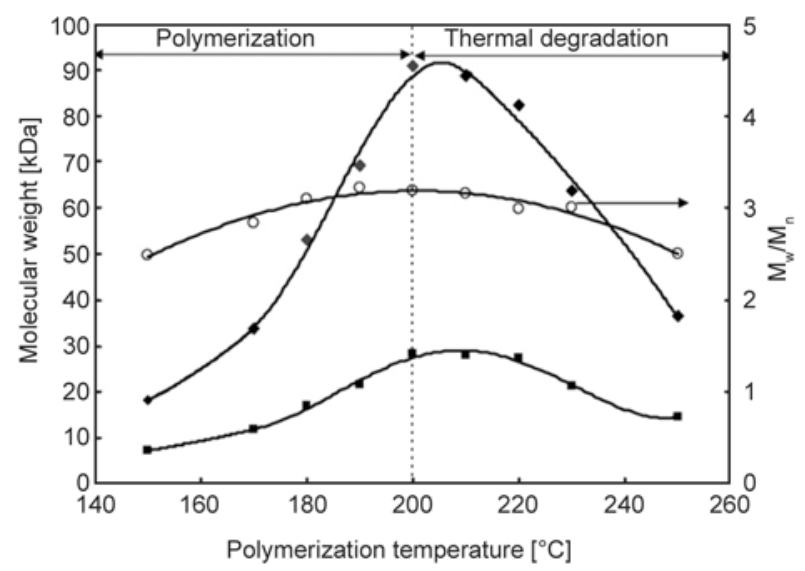

Figure 3. Effect of the PC reaction temperature on molecular weights of PLA polymers [11] ring-opening polymerization of the lactide intermediate resulting in PLA with a controlled molecular weight [14] (see Figure 2). On the other hand, the additional purification steps required for this process which was relatively complicated increased the cost of the polymer prepared using this method as compared to that of the polymer prepared using the PC method.

The molecular weights of the PLA polymer fabricated by the ORP method could be controlled by the residence time, temperature, consternation, and catalyst type. The ratio and sequence of D- and L-lactic acid units in the final polymer could also be controlled [15]. Recently, Cargill developed a new method to prepare the high-molecular weight PLA polymers from the lactide using a solvent free process and a novel distillation process, and a range of biodegradable PLA copolymers consisting of mesolactide or D-lactide have become commercially available since 2003 [5].

\section{Properties of polylactic acid 3.1. Rheological properties}

The rheological properties of PLA and its systems (PLA blends and composites) were investigated extensively using a variety of rheological characterization methods, such as capillary and rational rheometers [16-20]. Similar to all thermoplastic polymers, PLA exhibited Newtonian behavior at the low shear rates $\left(<10 \mathrm{~s}^{-1}\right)$ whereas it exhibited nonNewtonian behavior (shear thinning) at the high shear rates $\left(>10 \mathrm{~s}^{-1}\right)$ as shown in Figure 4. Many studies reported the rheological behavior of PLA and showed that PLA obeyed the power law (Equation (1)) over a certain range of shear rates and tem-

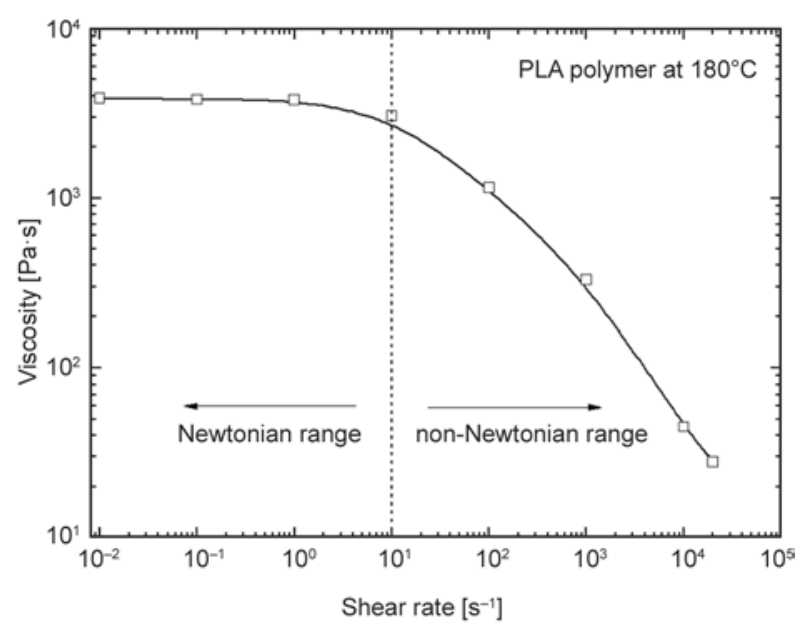

Figure 4. Viscosity curve of PLA at $180^{\circ} \mathrm{C}$ showing shear viscosity as a function of shear rate [26] 
peratures in the same way where other polymers obeyed [21-26]:

$$
\tau=K \gamma^{\mathrm{n}}
$$

where $\tau$ is the shear stress, $\gamma$ is the shear rate, $K$ is the consistency index, and $n$ is the non-Newtonian index. The value of $n$ described the deviation from Newtonian fluid flow behavior, so it was also called the flow behavior index. A higher $n$ value indicated that the shear rate had a less effect on the flow behavior. In other words, the changes in viscosity with the shear rate were not obvious. In addition, it was found that a PLA melt obeyed Equation (2) (Arrhenius equation form) at different shear rates and shear stresses:

$\eta=A \mathrm{e}^{\frac{\mathrm{E}}{\mathrm{RT}}}$

where $E$ is the flow activation energy, $A$ is the consistency related to the structure and formulation and $R$ is the gas constant. The flow activation energy reflected the temperature-sensitivity of the viscosity. Hence, a larger $E$ indicated a higher temperature sensitivity of the materials behavior.

The effects of the composition (L- and D-isomers) on the rheological properties of the PLA polymers were reported in the end of 1990s [16]. Two types of PLA were investigated, such as amorphous PLA containing 82\% L-lactide and 18\% D-lactide and semicrystalline PLA containing 95\% L-lactide and 5\% D-lactide. The results showed that the shear viscosity of the polymer increased with increasing L-isomer in the $\mathrm{L} / \mathrm{D}$-isomer mixture because of the increasing crystallinity of PLA, where the crystallinity increased with increasing L-isomer content [24]. In addition, Dorgan et al. [25] investigated the effect of the structure of PLA on the rheological properties using two different types of PLA, such as linear and branched. Their findings showed that the viscosity of branched PLA was higher than that of linear PLA in the Newtonian range, whereas viscosity of the branched PLA was lower in the non-Newtonian range. This was attributed to the shear thinning behavior of the polymer, resulting in a lower viscosity at high shear rates $[26,27]$.

\subsection{Mechanical properties}

The mechanical properties described the behavior of the material under the effect of different loading modes, such as tensile, impact, shear, and pressure. PLA had good mechanical properties (particularly tensile Young's modulus, tensile strength, flexural strength) compared to traditional polymers, such as polypropylene (PP), polystyrene (PS) and polyethylene (PE). However, the elongation at a break and the impact strength of PLA were lower than those of PP, PE, poly(ethylene terephthalate) PET, and polyamide (PA). Although the tensile strength and Young's modulus (good stiffness) of PLA were comparable to PET, the poor toughness limited its use in applications requiring plastic deformation at higher stress levels, which has motivated the considerable interest toward the toughening of PLA over last five years [28-30].

Oyama [31] reported the use of poly(ethylene-glycidyl methacrylate) (EGMA) as a toughening agent for PLA, and examined the effects of the agent content, annealing, and molecular weights of PLA (high and low molecular weights) on the impact strength. Their results are summarized in Figure 5. The impact strength of PLA could be improved by adding the agent $(20 \%)$ and by annealing at $90^{\circ} \mathrm{C}$ for $2.5 \mathrm{~h}$. Figure 5 shows that the distribution of the EGMA phase in the PLA matrix was finer in the material fabricated from the high molecular weight PLA (PLA-H) compared to that fabricated from the low molecular weight PLA (PLA-L). The higher melt viscosity of PLA-H than that of PLA-L was likely to create a higher shear force during melt-mixing. This facilitated the pull-out of the copolymers generated from the interface to the PLA matrix, leading to the generation of more co-polymers in the interfacial regions and the finer distribution of the EGMA phase. In a work reported by Sun et al. [32], ABS-grafted glycidyl methacrylate (ABS-g-GMA) was used as a toughening agent. They showed that the impact strength and elongation at a break of PLA could be improved by incorporating ABS-g-GM. In addition, styrene/acrylonitrile/glycidyl methacrylate copolymer (SAN-GMA) as the in situ compatibilizer and ethyltriphenyl phosphonium bromide (ETPB) as a catalyst were used to improve the toughness and compatibility of the PLA/ABS blend [33]. Hashima et al. [34] used a hydrogenated styrene-butadiene-styrene block copolymer (SEBS) using a reactive compatibilizer and poly(ethylene-co-glycidyl methacrylate) (EGMA) in the toughness process of the PLA/ABS blend. Recently, different compatibilizers, such as maleic anhydride-grafted ethylene propylene rub- 


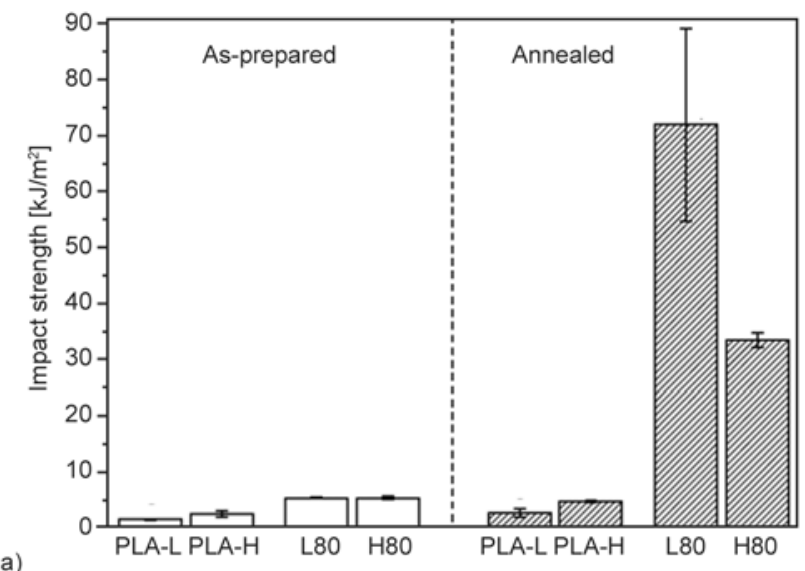

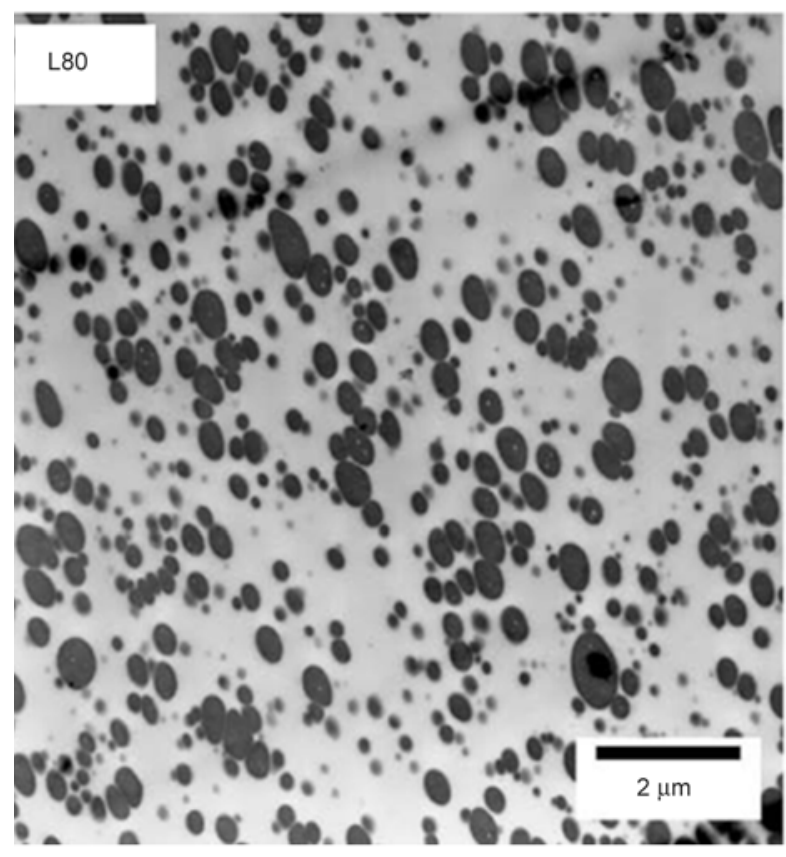

b)

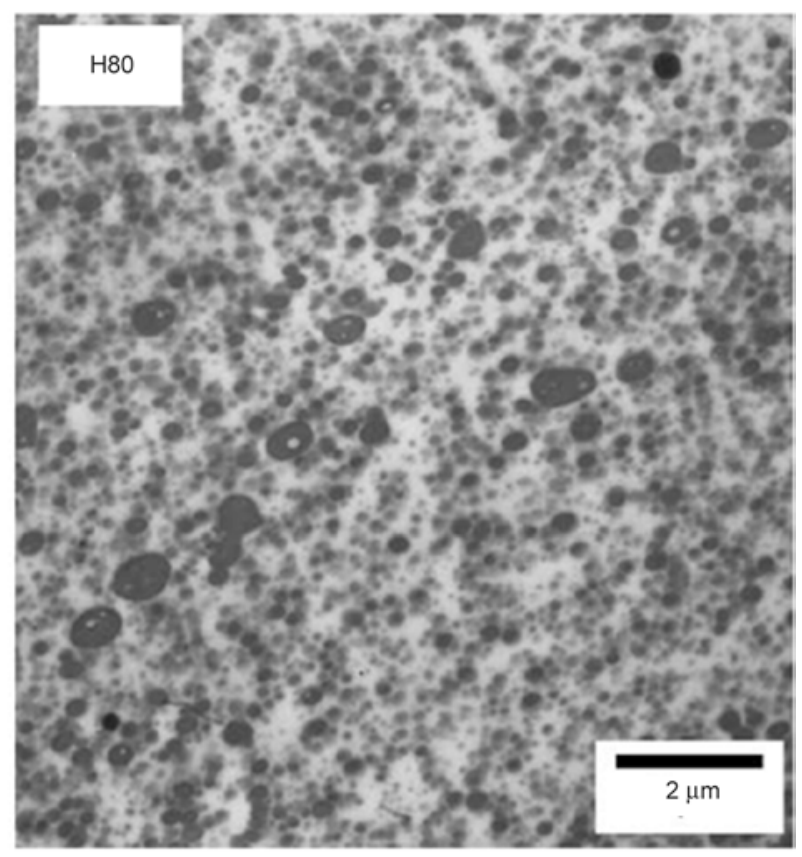

Figure 5. (a) Impact strength of PLA/EGMA blends before and after annealing treatment at $90^{\circ} \mathrm{C}$ for $2.5 \mathrm{~h}(\mathrm{~b}$ and c) morphologies of PLA/EGMA blends after annealing treatment at $90^{\circ} \mathrm{C}$ for $2.5 \mathrm{~h} \mathrm{[31].} \mathrm{L80} \mathrm{and} \mathrm{H80} \mathrm{are} \mathrm{PLA/EGMA}$ blends (20\% EGMA) prepared from low molecular weight PLA (PLA-L) and high molecular weight PLA (PLA$\mathrm{H})$, respectively

ber (EPR-g-MA), maleic anhydride-grafted styrene acrylonitrile copolymer (SAN-g-MAH), PE-epoxy, polycarbonate (PC), and glycidyl methacrylategrafted styrene-acrylonitrile copolymer (SAN-gGMA), were used in the blend consisting of PLA and ABS. The results showed that SAN-g-MAH was the most effective compatibilizer [35]. Wang et al. [36] also used PC to toughen PLA. Poly (butylene succinate-co-lactate) (PBSL) and epoxy (EP) were used as compatibilizers. The blends were prepared using a twin-screw extruder. Scanning electron microscopy (SEM) revealed a good interfacial adhesion between the blend components, which resulted in PLA materials with improved toughness and heat resistance. In addition, a ternary blend consisting of PLA, PC, and poly(butylene adipate-coterephthalate) (PBAT) was fabricated to obtain a novel material with unique properties including high toughness and good biodegradability [37]. Recently, a bio-based vulcanized unsaturated aliphatic polyester elastomer (UPE) was used to fabricate a super-tough thermoplastic blends containing PLA $[30,38]$. The results showed that the interfacial compatibilizations between PLA and UPE would lead to improved tensile and impact toughness with values up to $\sim 99 \mathrm{MJ} / \mathrm{m}^{3}$ and $\sim 586 \mathrm{~J} / \mathrm{m}$, respectively, as compared to those of $\sim 3.2 \mathrm{MJ} / \mathrm{m}^{3}$ and $\sim 16.8 \mathrm{~J} / \mathrm{m}$ for neat PLA, respectively. 


\subsection{Thermal properties}

PLA is a semi-crystalline or amorphous polymer with a glass transition temperature $\left(T_{\mathrm{g}}\right)$ and melting temperature $\left(T_{\mathrm{m}}\right)$ of approximately $55^{\circ} \mathrm{C}$ and $180^{\circ} \mathrm{C}$, respectively. The thermal properties of PLA could be affected by different structural parameters, such as molecular weights and composition (stereoisomers content). The $T_{\mathrm{g}}$ was related to the molecular weight of the polymer, and the relation between $T_{\mathrm{g}}$ and molecular weight was described by Equation (3) (Flory-Fox equation):

$T_{\mathrm{g}}=T^{\infty}-\frac{K}{M}$

where $T^{\infty}$ is the glass transition temperature at the infinite molecular weight, $M$ is the molecular weight, and $K$ is a constant related to the free volume of the end groups for the polymer chains. This relationship was reported on PLA polymers by Dorgan et al. [39], where the effect of molecular weights and composition ( $L / D$ ratio) on the thermal properties of PLA polymers was investigated. Figure 6 shows $T_{\mathrm{g}}$ values of several PLA polymers with different molecular weights and compositions. The curves presented in Figure 6 were fit to the data expected by Fox-Flory equation (Equation (3)) of the dependence of $T_{\mathrm{g}}$ on number-average molecular weights $\left(M_{\mathrm{n}}\right)$. The $T_{\mathrm{g}}$ increased rapidly with increasing molecular weight but, then, it reached a constant value. The effect of the L-stereoisomer content on the $T_{\mathrm{g}}$ of the polymer showed that, with increasing the amount of L-stereoisomer, the glass transition temperature at the infi-

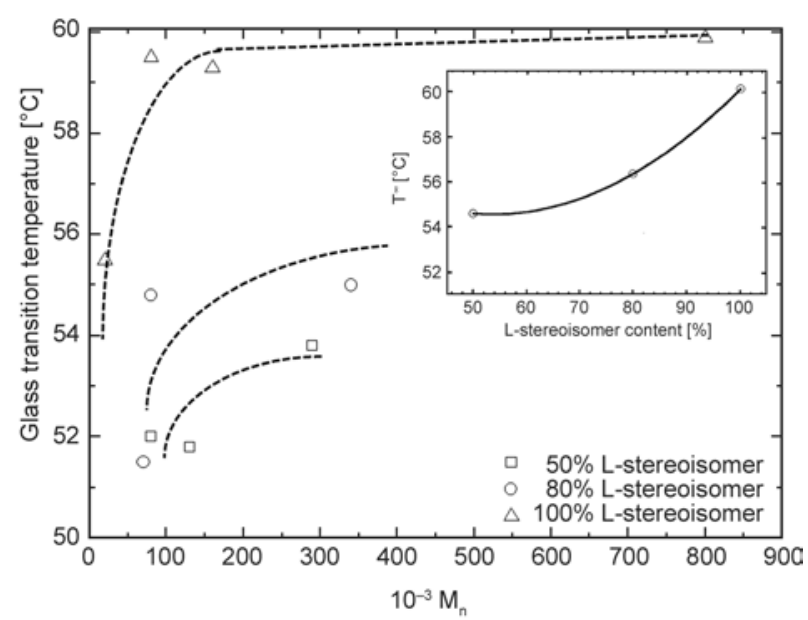

Figure 6. Glass transition temperatures $\left(T_{\mathrm{g}}\right)$ of PLA polymers with different L-stereoisomer contents as a function of number-average molecular weights $\left(M_{\mathrm{n}}\right)$ [39] nite molecular weight increased as shown in Figure 6.

In addition, several studies reported the crystallization behaviors of PLA [40-43] showed that PLA could be either amorphous or semi-crystalline depending on its stereochemistry and thermal history. The crystallinity of PLA was determined commonly by differential scanning calorimetry (DSC), and by measuring the heat of fusion, $\Delta H_{\mathrm{m}}$, and the heat of crystallization, $\Delta H_{\mathrm{C}}$. The crystallinity $(C[\%])$ can be calculated using Equation (4):

$C[\%]=\frac{\Delta H_{\mathrm{m}}-\Delta H_{\mathrm{C}}}{93,1} \cdot 100$

where the constant, $93.1 \mathrm{~J} / \mathrm{g}$, is the $\Delta H_{\mathrm{m}}$ for $100 \%$ crystalline PLLA or PDLA homo-polymers. The effect of stereochemistry on the crystallization behavior of PLA was investigated by Pyda et al. [44]. The results from DSC in Figure 7 showed that PLA polymers with $\sim 8$ and $\sim 16 \%$ D-stereoisomer was amorphous even after $15 \mathrm{~h}$ of isothermally treatment at $145^{\circ} \mathrm{C}$. In contrast, the heat treatment at $145^{\circ} \mathrm{C}$ of PLA polymers with $1.5 \% \mathrm{D}$-stereoisomer resulted in a large endothermic melting peak around $177^{\circ} \mathrm{C}$, suggesting that PLA containing 1.5\% D-stereoisomer was semi-crystalline. In addition to the stereo-chemistry of PLA polymers, the crystallization behavior could be affected by processing parameters during the production of PLA sheets, stretch blow molding of bottles, and fiber spinning. Figure 8 shows the crystallization behavior of PLA sheets with respect to draw ratio and drawing temperature [45]. As shown in Figure 8, the area below the crystallization peak increased with increasing draw ratio, indi-

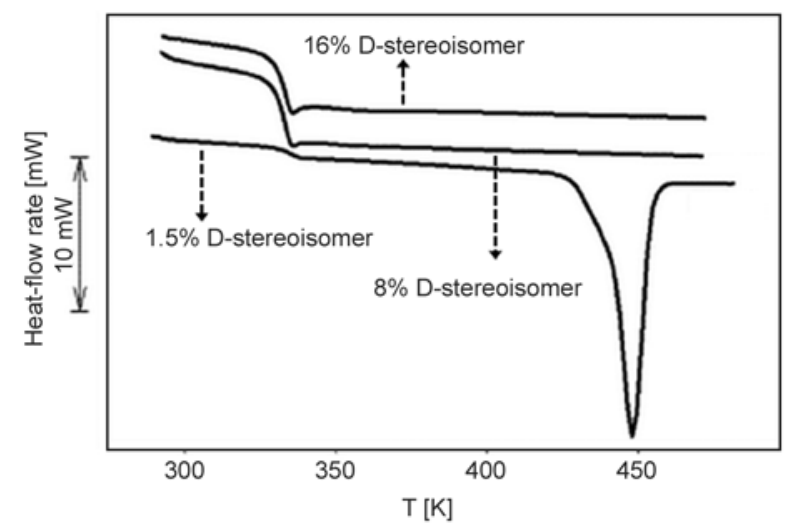

Figure 7. Differential scanning calorimetry (DSC) curves of PLA polymers with different contents of Dstereoisomer: $\sim 1.5, \sim 8$, and $\sim 16 \%$ [44] 

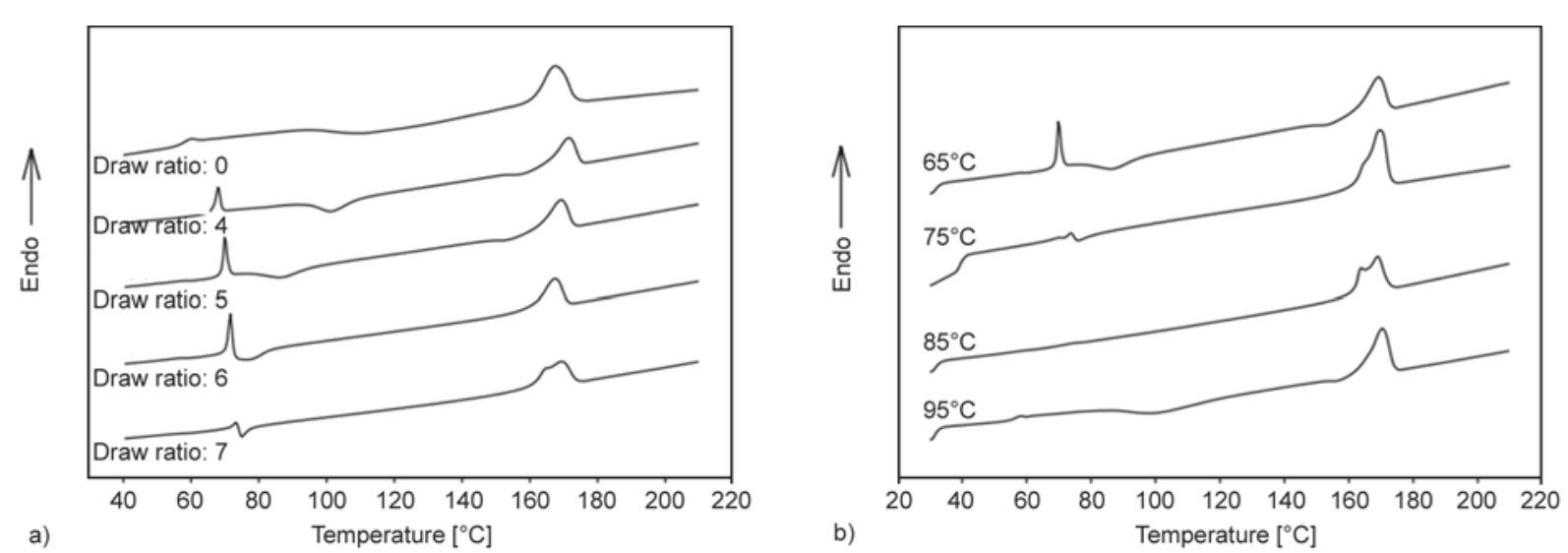

Figure 8. (a) Differential scanning calorimetry (DSC) curves of PLA samples stretched at $0.17 \mathrm{~s}^{-1}$ and at $65^{\circ} \mathrm{C}$ for various draw ratios of $0,4,5,6$, and 7 (b) DSC curves f PLA samples stretched at $0.17 \mathrm{~s}^{-1}$ with draw ratio of 5 for various drawing temperatures of $65,75,85$, and $95^{\circ} \mathrm{C}[45]$

cating the increasing of the crystallinity in PLA sheets. In addition, highly oriented PLA sheets were obtained at drawing temperature of $80^{\circ} \mathrm{C}$. It was reported that at this temperature a combination of fast crystallization and slow relaxation could be achieved resulting in highly-oriented PLA sheets.

Polymer processes, such as extrusion, injection, and spinning, could result in the thermal degradation of PLA, hence the thermal stability of PLA was investigated widely. Pillin et al. [46] examined the effect of a thermo-mechanical treatment on the properties of PLA. The rheological and mechanical properties of PLA subjected to thermo-mechanical cycles were determined. The results showed that the viscosity of PLA decreased by a factor of 0.82 after the first cycle of treatment. In addition, only the tensile modulus remained constant with the thermo-mechanical cycles, whereas tensile strength and elongation at a break decreased after the thermo-mechanical treatment. The effect of a multi-extrusion process on the tensile properties, impact strength, melt flow index, and permeability of water vapor and oxygen of PLA was reported [47]. The results showed that the tensile strength and impact strength of PLA decreased slightly after the multi-extrusion process, whereas the melt flow index and permeability of water vapor and oxygen were increased by the multiextrusion cycles. Al-Itry et al. [48] examined the thermal stability of PLA processed by the extrusion process at different processing temperatures by analyzing the rheological properties of the extruded PLA. Figure 9 shows the effect of the processing temperature on the viscosity of the extruded polymer at different temperatures along with the related molecular weights. The viscosity of the extrudate decreased with increasing extrusion temperature because of the decreasing molecular weights associated with the shear deformation imposed by the extrusion screw. To enhance the thermal stability of PLA during the extrusion process, chain extenders
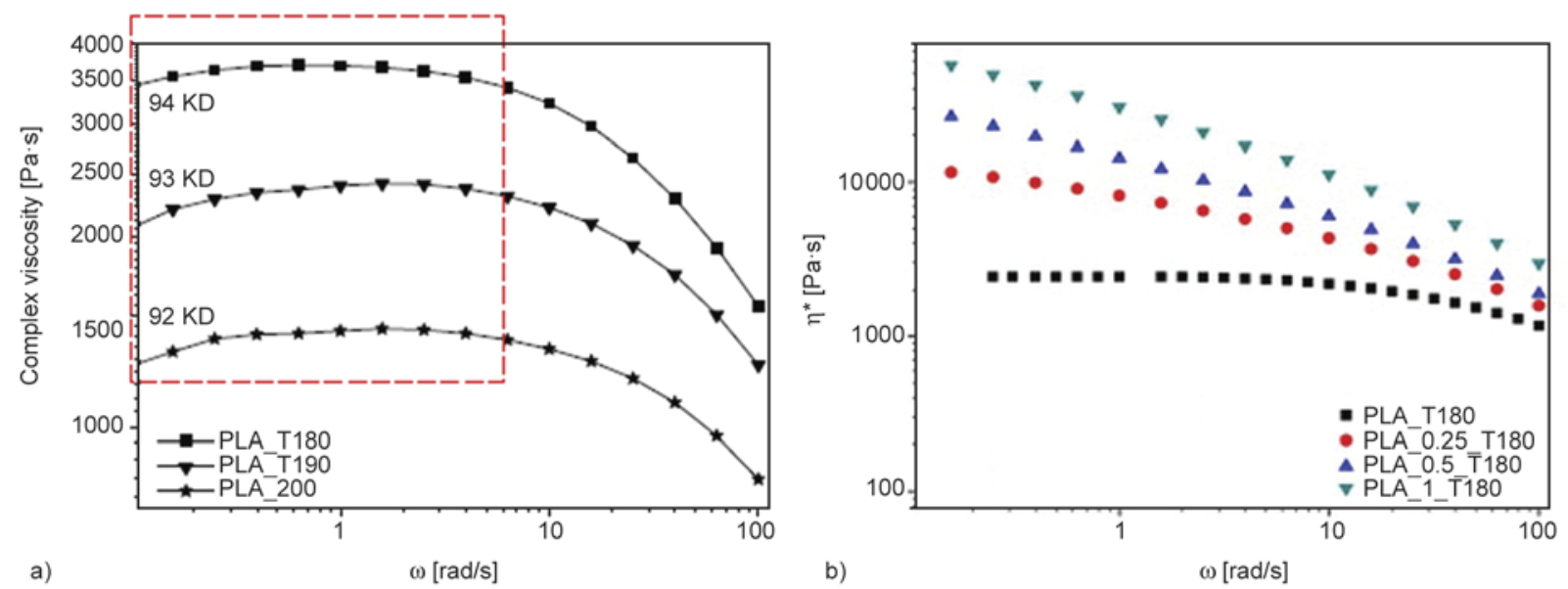

Figure 9. (a) Effect of the extrusion temperature on the complex viscosity of PLA (b) effect of chain extenders on the complex viscosity at $180^{\circ} \mathrm{C}$ [48] 
were incorporated with the polymer, which resulted in an increased complex viscosity of the extruded polymer. Recently, the effects of PS, as a second component, on the thermal degradation of PLA polymer was studied [49]. The results showed that the presence of PS in the blend improved the thermal stability of PLA, which was attributed to the high thermal stability of PS.

\subsection{Barrier properties}

Because PLA was used in packaging applications [5], there has been a continuing need for a clear understanding of the barrier properties of PLA. PLA processed barrier properties that were higher than those of PE, PP and similar to PS but lower than those of PET (Figure 10). Auras and coworkers [50, 51] studied the barrier properties of PLA and compared them with those of PET and PS. They showed that the permeability coefficients of $\mathrm{CO}_{2}, \mathrm{O}_{2}, \mathrm{~N}_{2}$, and $\mathrm{H}_{2} \mathrm{O}_{(\mathrm{g})}$ for PLA were lower than that of PS, but higher than that of PET. In general, the crystallinity of PLA strongly affected the barrier properties of the polymer, where the decrease in crystallinity was a nega-

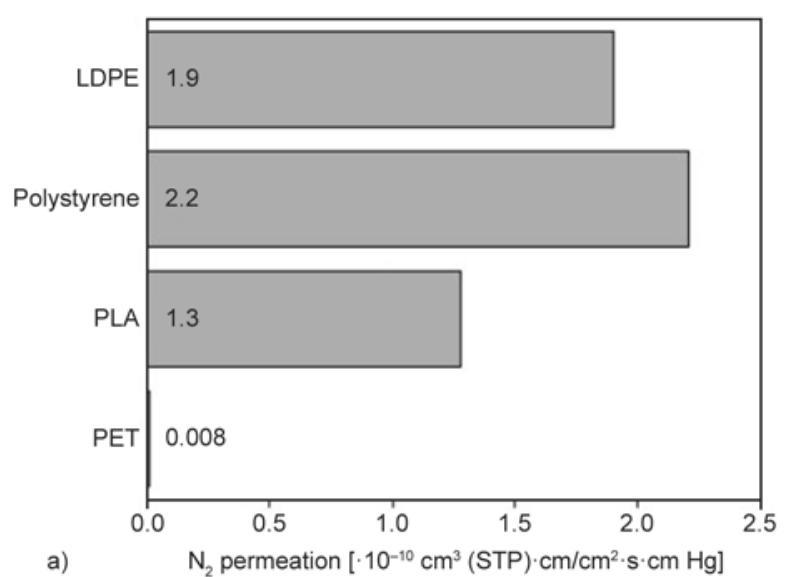

a)

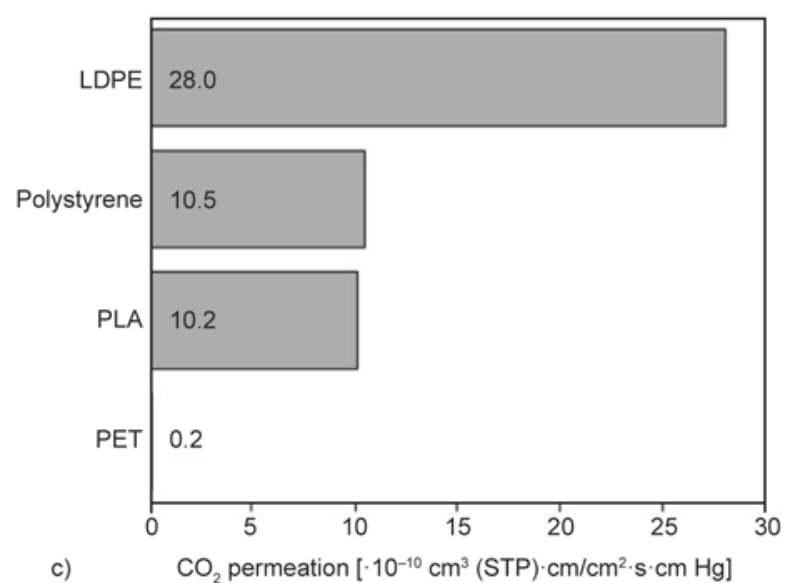

tive aspect in terms of the mechanical and barrier properties.

Accordingly, this issue motivated further interest in an improvement of the barrier properties of PLA. Many studies have reported improvement of the barrier properties of PLA. Thellen et al. [52] investigated montmorillonite-layered silicate/PLA composites in terms of the barrier properties. The enhancement of $50 \%$ in the oxygen barrier properties was noted. Chaiwong et al. [53] examined the effects of a plasma treatment on the barrier properties of PLA. The results showed that the plasma treatment had no effect on the barrier properties of PLA. In addition, Jamshidian et al. [54] reported the effects of a synthetic phenolic antioxidant (SPA) structure on the mechanical, thermal, and barrier properties of PLA. They found that the SPAs had no effect on the oxygen barrier properties of PLA, even though the other properties (thermal and mechanical properties) were affected. Bao et al. [55] examined the effects of annealing treatment on the barrier properties of films fabricated from PLA polymers. They reported that the barrierity of the films increased after annealing

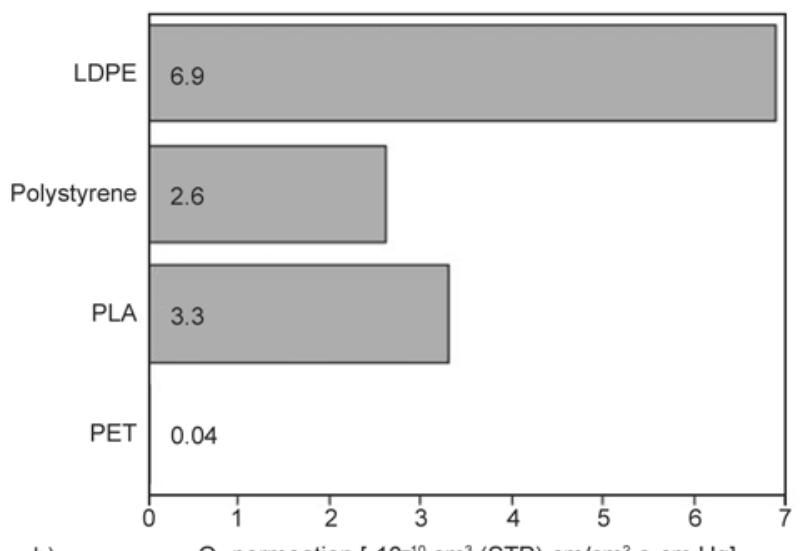

b) $\quad \mathrm{O}_{2}$ permeation $\left[\cdot 10^{-10} \mathrm{~cm}^{3}(\mathrm{STP}) \cdot \mathrm{cm} / \mathrm{cm}^{2} \cdot \mathrm{s} \cdot \mathrm{cm} \mathrm{Hg}\right]$

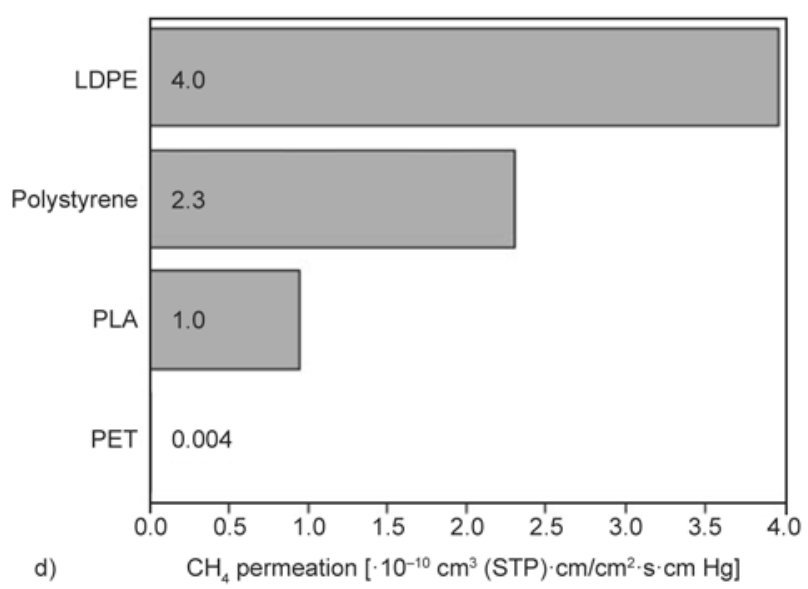

Figure 10. Barrier properties of PLA in comparison to other common polymers at $30^{\circ} \mathrm{C}$ (a) $\mathrm{N}_{2}$, (b) $\mathrm{O}_{2}$, (c) $\mathrm{CO}_{2}$, and (d) $\mathrm{CH}_{4}[25]$ 
due to the increasing crystallinity induced by annealing.

\subsection{Processing technologies}

Polymer processing technologies were processes in which a polymeric material was converted to a finished product involving shaping, compounding, and chemical reactions. In the compounding process, additives, such as plasticizers, stabilizers, pigments, and fillers, were incorporated with the polymer matrix using different kinds of compounders. Accordingly, plasticizers were added to enhance the flexibility of PLA.

Al-Mulla et al. [56] reported the use of epoxidized palm oil as a plasticizer for PLA. PLA and plasticizer were blended using the solution method under which chloroform was used as a solvent. The ductility of PLA was improved by the addition $20 \%$ plasticizer, where the elongation of PLA increased by a factor of 8 as compared to pure PLA when the plasticizer was added. In other work [57], two commercial grades of polymeric adipates were used as plasticizers. A very good plasticization effect of these materials was reported. It was found that the elongation at break increased from $6 \%$ in the pure polymer up to approximately $500 \%$ for $20 \mathrm{wt} \%$ of both plasticizers. Such an increase in ductility was correlated directly with the decreases in $T_{\mathrm{g}}$ due to the compatibility between the plasticizers and PLA in the composite (Figure 11).

Polymer processing technologies, including extrusion, injection molding, and blow molding, were known for more than 100 years. In general, it was essential to dry the PLA pellets before the melt pro-

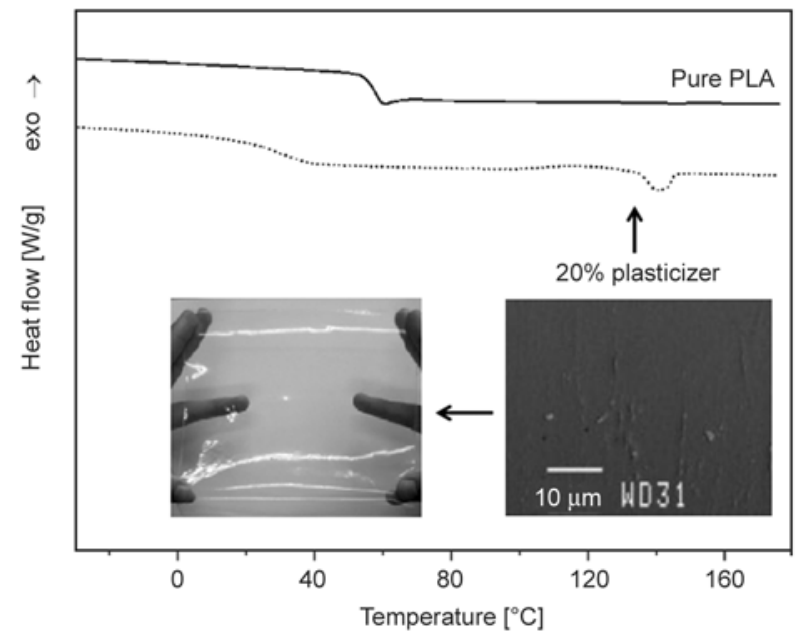

Figure 11. Transparent film of PLA/polyadipates blend and related thermal and structural properties [57] cessing to reduce the moisture level, which could enhance the degradation of the ester linkage in PLA during the melting process of the polymer. Typically, the polymer was dried to less than $0.01 \mathrm{wt} \%$. Amorphous pellets of PLA were dried below their $T_{\mathrm{g}}$ and because $T_{\mathrm{g}}$ depended on the stereo-chemistry of the monomers, the drying temperature depended on the composition of the polymer (PLA). Natureworks LLC, which was one of the main suppliers of PLA polymers, has recommended that PLA resins should be dried to moisture contents of $0.025 \mathrm{wt} \%$ or below [58]. In a single screw extrusion process, the polymer was dragged continuously along a screw through regions of high temperature and pressure. Using this process, constant profile articles, such as films, tubes, and pipes, were produced through the rotation of a screw that mixed and pushed the melts to the final articles. The general screws comprised of three main zones: the feeding zone, plasticizing (pressure) zone and metering (pumping) zone, where the temperature increased gradually from the feeding zone to the metering zone. Normally, extruders were described using several parameters, such as length/ diameter ratio of the screw ( $L / D$ ratio) and compression ratio, which was the ratio of the channel depth in the feed zone to that in the metering zone. Many materials might require a specific screw, which was related to the structure and thermal stability of the fabricated materials, such as the PVC screw and PA screw. In the case of PLA, a screw with a low shear ( $L / D$ ratio between 24 and 40 ) was required to prevent the degradation induced by thermo-mechanical shearing during the extrusion process $[58,59]$.

In the injection molding, the processed material was molten using a similar screw to that used in the extrusion process, and it was then pushed (injected) using the same screw to the mold which provided the final shape of the product. The injection conditions were related to many factors, such as the chemical structure, molecular weight, morphology, and final product properties. In general, the injection temperature and pressure, which were related to the volume of an injected part through pressure-volumetemperature diagram (PVT diagram), were the most effective processing parameters in injection modeling. Sato et al. [60] reported the PVT diagram of PLA and other biodegradable polymers, and they used these diagrams to predict the shrinkage behavior of the final products fabricated from biodegradable polymers by injection molding. In addition, PLA bot- 
tles used in food applications were molded by a blow molding process. In the first step of this process, the parison (pre-form part) was shaped using the injection molding process. The parison was then moved to blow the molding machine where it was stretched and blown after heating to temperatures between $85-110^{\circ} \mathrm{C}$ which was generally higher than the $T_{\mathrm{g}}$ and lower than $T_{\mathrm{m}}$ of the polymer in the axial direction, resulting in a biaxial orientation of the polymer, which in turn led to high mechanical and barrier performance of the shaped bottles.

\subsection{Biodegradation properties}

Biodegradation had a range of definitions but most definitions were based on the same concept: the action of microorganisms on the material and its conversion into carbon dioxide or methane and water. In addition, according to the Japanese Biodegradable Polymer Society (JBPS), the biodegradation was a process in which the polymer was decomposed to water and carbon dioxide through the action of microorganisms commonly existing in the natural environment, and the JBPS called this type of polymer (biodegradable polymers) Green Plastic. Two types of biodegradation were known, and the biodegradation products were aerobic or anaerobic. No residue mean complete biodegradation and complete mineralization was established when the original substrate was converted completely to the gaseous products. The rate of degradation was affected by a range of factors, such as the medium of biodegradation including temperature and humidity, and the chemical parameters of PLA including molecular weights and composition.

Many methods were used to measure the biodegradation rate. Some of them depended on measuring the gaseous products $\left(\mathrm{CO}_{2}\right.$ or $\left.\mathrm{CH}_{4}\right)$ as a function of time. In addition, the structural, thermal, and morphological properties of the sample were monitored during the biodegradation test. Unlike weight loss, which reflected the structural changes in the polymer, $\mathrm{CO}_{2}$ and $\mathrm{CH}_{4}$ measurements provided an indicator of the ultimate biodegradability (i.e. mineralization) of the polymer. In these two cases, real or simulated (controlled) composting conditions were used (outdoor or indoor, respectively).

PLA degradation was studied in animal and human bodies for medical applications like implants, surgical sutures, and drug delivery materials. In these environments, PLA is initially degraded by hydrolysis and the soluble oligomers formed are metabolized by cells. On the other hand, PLA degradation upon disposal in the environment is more challenging because PLA is largely resistant to attack by microorganisms in soil or sewage under ambient conditions. The polymer must first be hydrolyzed at elevated temperatures (about $58^{\circ} \mathrm{C}$ ) to reduce the molecular weight before biodegradation can commence. The hydrolysis reaction followed first order kinetics, as demonstrated previously and fitted to the Equation (5) $[61,62]$ :

$M_{\mathrm{W}}=a \mathrm{e}^{\mathrm{bt}}$

where $a$ and $b$ are constants and equal to $230 \mathrm{kDa}$ and $0.18 \mathrm{~s}^{-1}$, respectively, and $t$ is the time in days. Recently, the biodegradation behavior of PLA films buried in real soil environments for several months was investigated by measuring thermal and morphological properties of the residual degraded samples [63]. The analyses showed that the PLA sample surface had many corrosive holes after four months degradation, clearly showing that the PLA was degraded (Figure 12). Kale and coworkers [64, 65] reported the biodegradation performance PLA bottles in real composting conditions $\left(\sim 58^{\circ} \mathrm{C}\right.$ and $\sim 60 \%$ relative humidity $(R H)$ ) by measuring the variations in the molecular weight of the degraded polymer with the time. The results showed that the molecular weight increased slightly on the first day, which was attributed to cross-linking or recombination reactions. Major fragmentation which produced decomposition of the polymer chain to shorter oligomer chains and monomers was observed from the fourth day onwards. Figure 13 shows the variation in the molecular weight and polydispersity index (PDI) of the PLA bottles as a function of the degradation time. Molecular weight values below $5 \mathrm{kDa}$ could be obtained after 57 days of the degradation, which was in consistent with the values calculated from Equation (5).

However, the biodegradability rate of PLA polymers in soil under real conditions was lower than the rate of waste accumulation. Therefore, several works reported the mixing of PLA with natural materials such as starch and cellulose in order to improve its biodegradability. For instance, in a work reported by Ohkita and Lee [66], PLA/corn starch (CS) composites were investigated in applications where fast biodegradable was required. The results of biodegrada- 

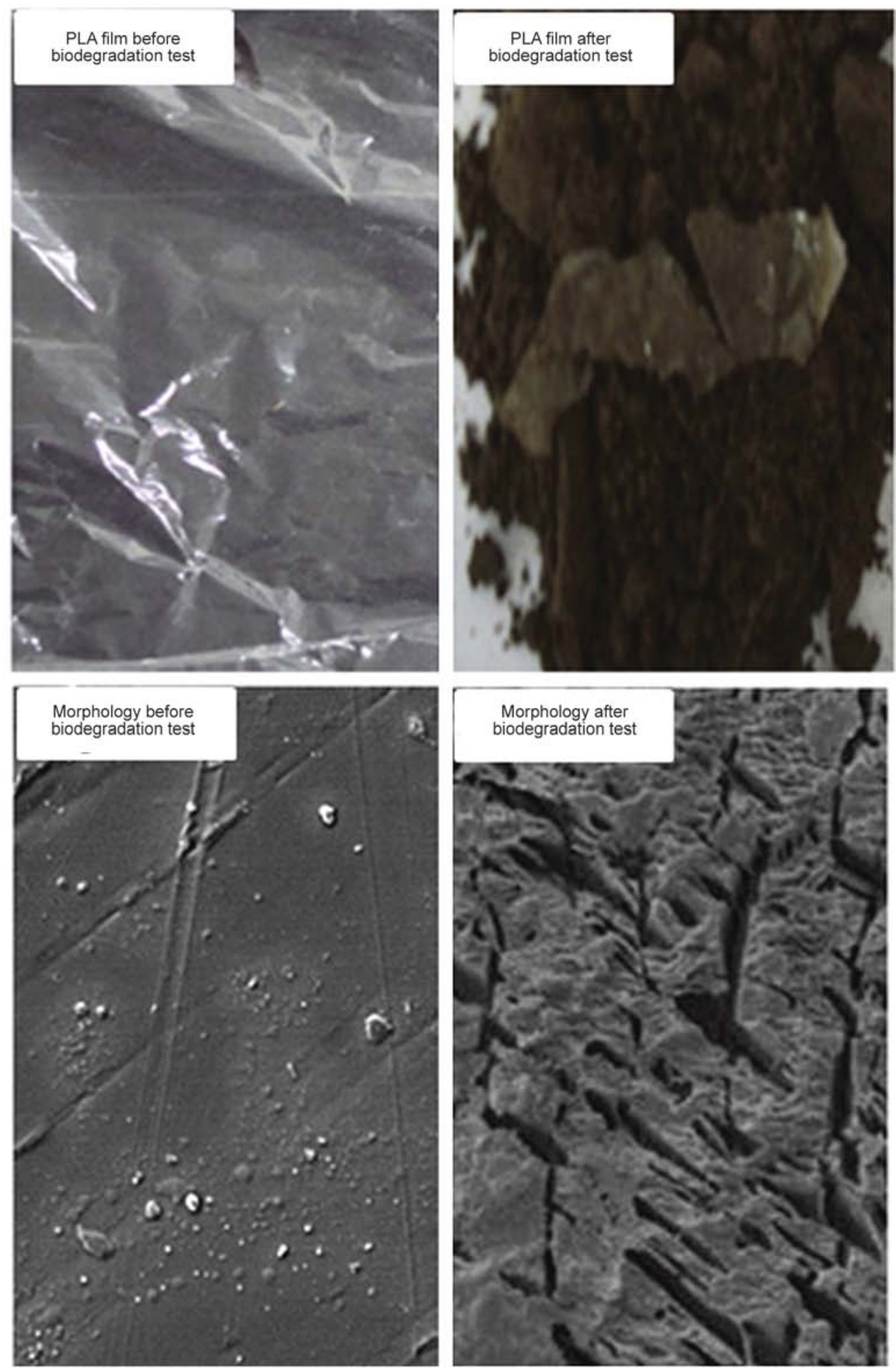

0 month

4 months

Figure 12. PLA film samples and SEM images before the biodegradation test and after 4 months of the biodegradation test [63]

tion tests of the composites performed in soil under real composting conditions $\left(\sim 30^{\circ} \mathrm{C}\right.$ and $\left.\sim 80 \% R H\right)$ are presented in Figure 14. It is clearly seen from Figure 14 that the biodegradation rate increased with increasing corn starch content in the prepared composites due to the high biodegradability of starch materials. 


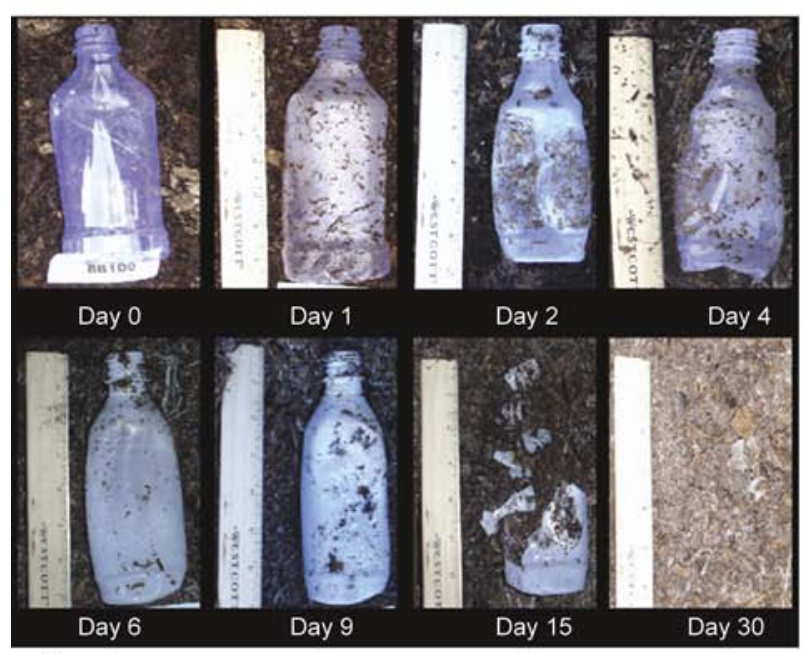

a)

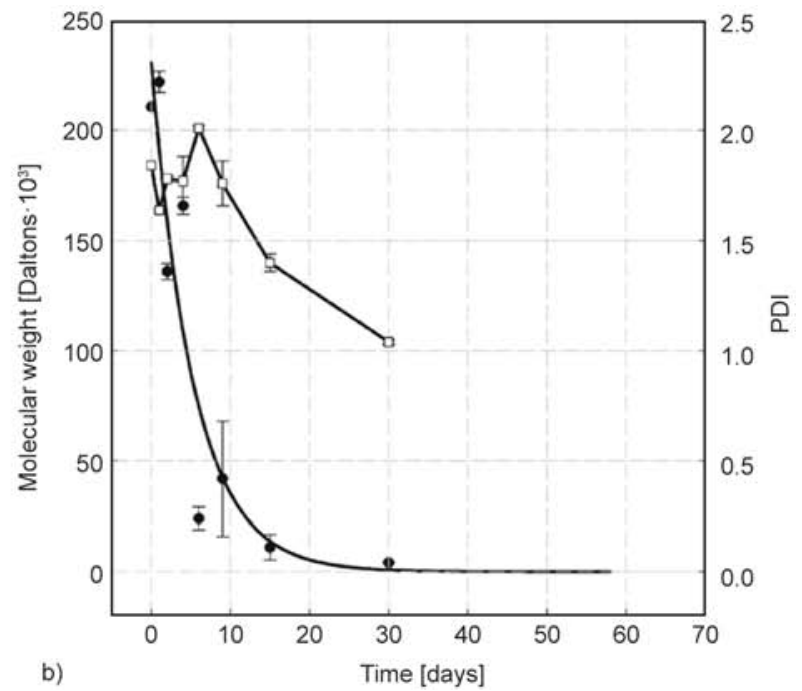

Figure 13. (a) Biodegradation of PLA bottles [64] (b) variation in the molecular weight and PDI as a function of the biodegradation time under real composting conditions [65]
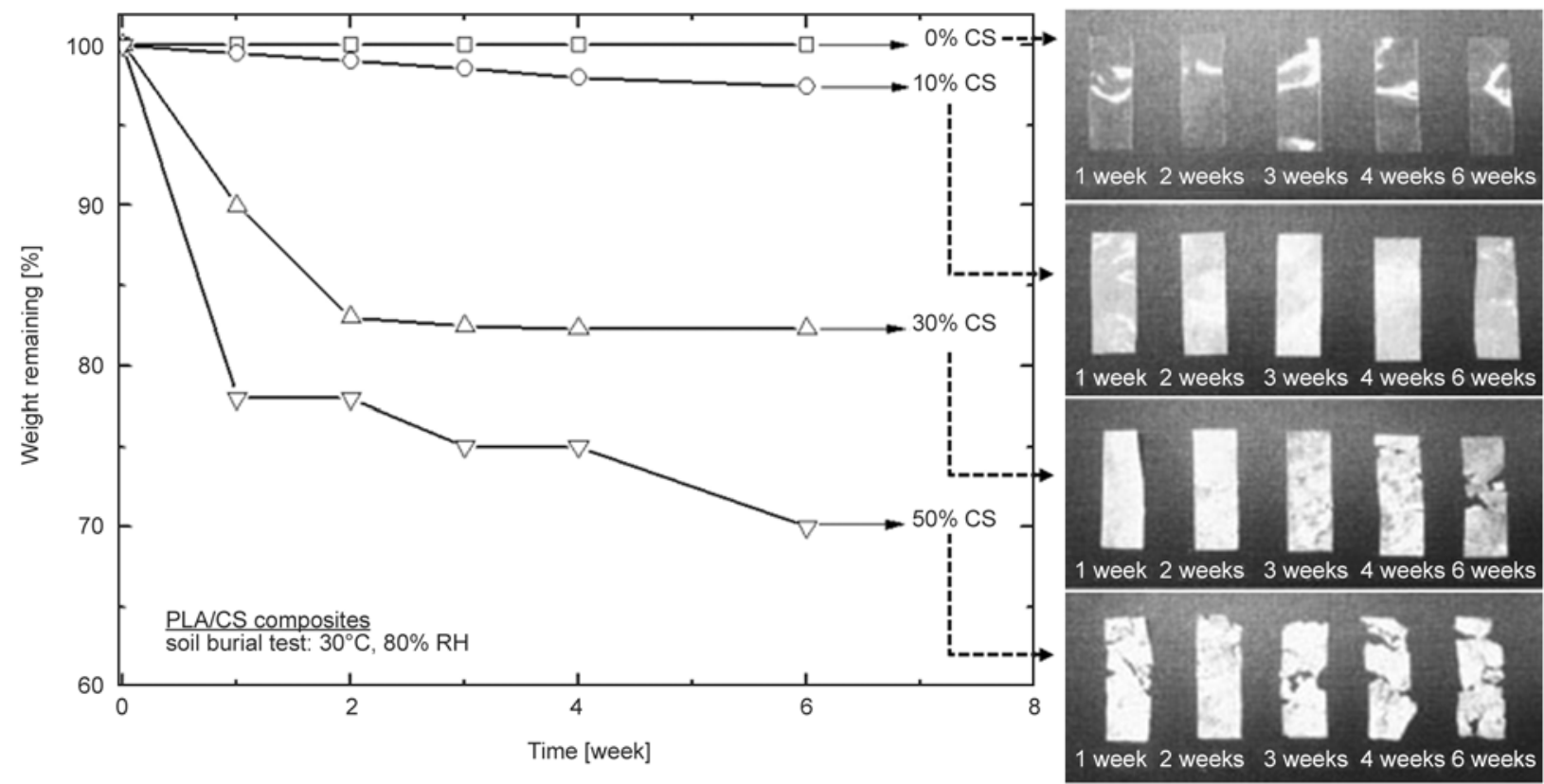

Figure 14. Weight remaining and appearance for samples fabricated from PLA and PLA/corn starch (CS) composites as a function of degradation time in burial tests at $30^{\circ} \mathrm{C}$ with $30 \% R H$

\section{Medical applications \\ 4.1. Tissue engineering}

Tissue engineering (TE), a term first coined in 1987 [67], has been a multidisciplinary field in an effort to find a solution for critical medical problems, such as tissue loss and organ failure using the development and application of knowledge in chemistry, physics, engineering, and life sciences [68]. PLA and their copolymers were a family of linear aliphatic polyesters that were used most frequently in tissue engineering. The medical applications of PLA arose from its biocompatibility as well as its dissolvabil- ity in the body by the simple hydrolysis of the ester backbone to produce non-harmful and non-toxic degradation compounds. For medical applications of PLA polymer, hydrolysis would be the most important degradation mode which differed from the biodegradation mode explained in the preceding section.

PLA has been investigated for tissue engineering applications, such as bone scaffolds, because of the good biocompatibility of this polymer [69], but it had poor mechanical properties for applications to tissue engineering. The mechanical properties of PLA 


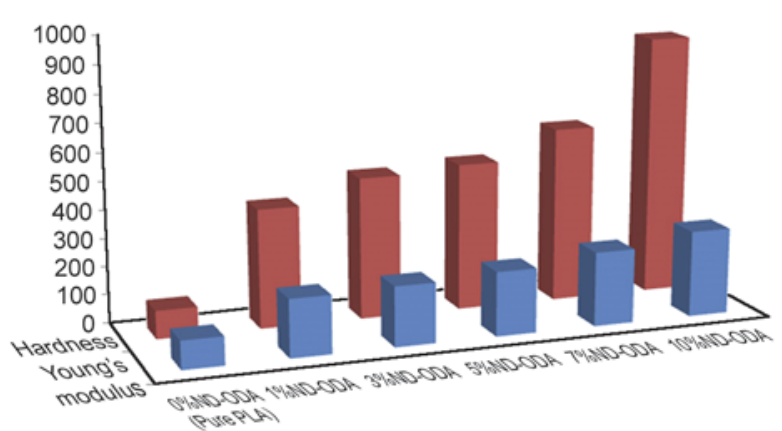

Figure 15. Hardness and Young's modulus of PLA/NDODA polymer composites as compared to pure PLA [70]

were improved using a range of methods, such as blending, composites forming, and co-polymerization.

Zhang et al. [70] prepared PLA/octadecylaminefunctionalized nano-diamond (ND-ODA) composites for use in tissue engineering. The composites were prepared using a solution method where PLA was dissolved in chloroform whereas ND-ODA was dispersed in chloroform and sonicated. The PLA solution and ND-ODA dispersion were then mixed, and the chloroform was vaporized to obtain thin films of the composites. Various loads of ND-ODA in the composite preparations (up to $10 \mathrm{wt} \%$ ) were incorporated. The results showed that the mechanical properties of PLA (Young's modulus and hardness) were improved after mixing with ND-ODA (Figure 15) because of the good affinity between the polymer and the filler in the composites indicating the applicability of this composite for tissue engineering. In addition, the toxicity and biocompatibility

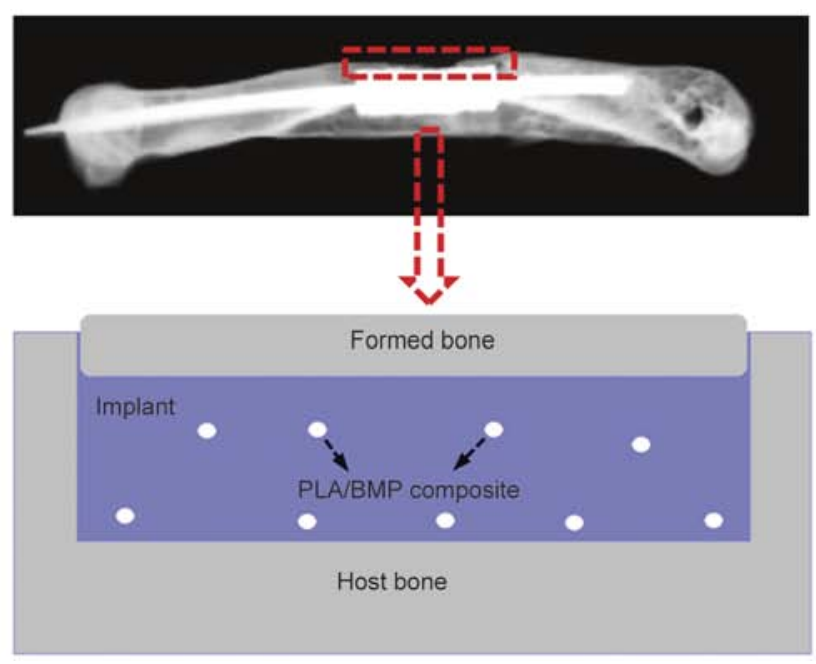

experiments showed that the ND-ODA and composites were nontoxic to murine osteoblasts.

In addition, PLA and its copolymers, such as PLApolyethylene glycol block copolymer (PLA-PEG) and PLA-p-dioxanone-polyethylene glycol block copolymer (PLA-p-DPEG), were used as carriers for bone morphogenetic proteins (BMPs). BMPs were biologically active molecules capable of inducing new bone formation, and they were expected to be used clinically in combination with biomaterials, such as bone-graft substitutes to promote bone repair. Saito and Takaoka [71] examined the usefulness of PLA as a carrier of BMP and the effect of PLA on the osteoinduction of demineralized bone, and they found that PLA was a good candidate as a carrier for BMP. Low molecular weight PLA was mixed with BMP to form a composite that was then implanted in the host bone, and new bone cells were formed during the degradation of a PLA matrix in the composite as shown in Figure 16 [72]. On the other hand, the newly-formed bone was too small in quantity. Therefore, PLA copolymers were used to solve these problems with low molecular weight PLA. Chang et al. [73] prepared a novel porous PLA composite scaffold and evaluated the capacity of the scaffold as a carrier for the recombinant bone morphogenetic protein 2 (rhBMP2). The results showed that the PLA scaffolds exhibited a sufficient capability of carrying rhBMP2 to induce bone formation in two weeks.

\subsection{Wound management}

PLA and its copolymers were used in a range of applications related to wound management, such as

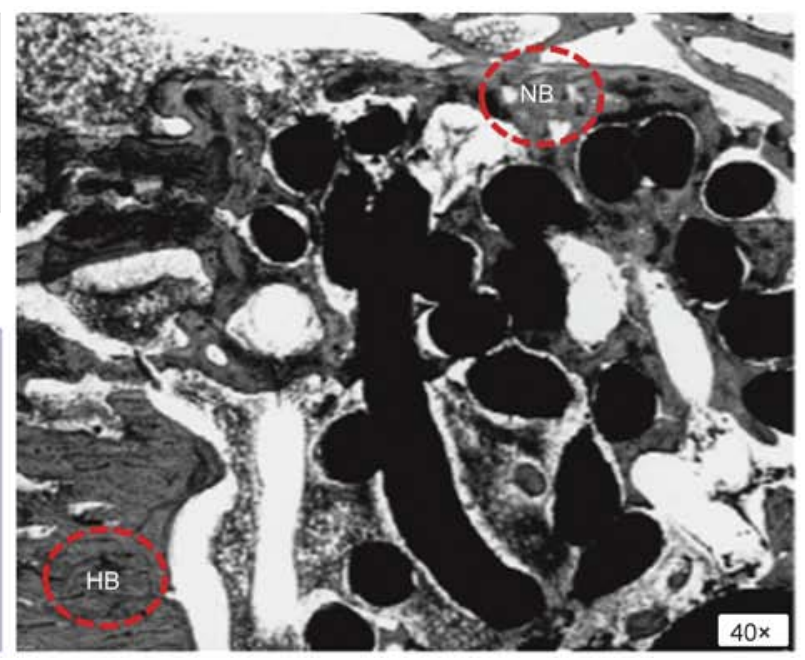

Figure 16. Bone-defect treatment using implants containing a composite of PLA and BMP. The composite exuded from pores of the implants and formed a layer of new bone (NB) covering the surface of the biomaterials. The NB encased the implant and thus enhanced biological fixation of the biomaterials to the host bone (HB) $[71,72]$ 
surgical sutures, healing dental extraction wounds, and preventing postoperative adhesions. Li et al. [74] evaluated the efficacy and feasibility of PLA ureteral stents for the treatment of ureteral war injuries. The stents made of PLA were reliable in the treatment of ureteral war injuries where PLA stents were degraded so that they were removed from the body. Therefore, PLA stents represented a promising future for the treatment of ureteral war injuries. Qin et al. [75] used PLA based on polymer blends to prevent postoperative adhesions. In that study, PLA was blended with polytrimethylene carbonate (PTMC) using the solution method where the two polymers were mixed and dissolved in acetoacetate. After the polymeric solution was poured into a Teflon plate, the solvent was evaporated to obtain a thin film. The films prepared from the blend at different ratios were prepared and compared with those of pure PLA. Traditional characterizations of the films (thermal and mechanical characterizations) as well as the medical study on the films were performed. The

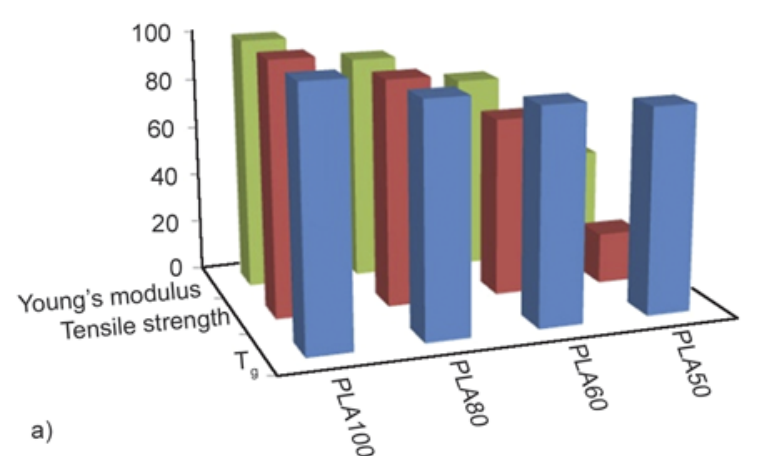

results showed that the blends were more flexible than pure PLA, whereas the tensile strength, Young's modulus, and glass transition temperature of pure PLA were higher than those of the blends (Figure 17). The decreasing $T_{\mathrm{g}}$ with increasing PTMC content in the blend indicated the compatibility between the two components (PLA, PTMC) [76, 77]. The greater flexibility of the blends compared to pure PLA made them more suitable for covering the wound where the stiff film of pure PLA could not be covered freely over the wound when it was implanted in the body. The cytotoxicity of the blend films was examined by measuring the amount of succinate dehydrogenase (SDH) released by the cells incubated with the blend films. The results suggested that PLA and PLA/ PTMC blend films were not cytotoxic. Brekke et al. [78] used PLA to improve the ability of dental extraction wound healing, and they reported that a PLA surgical dressing material reduced the incidence of mandibular third molar extraction wound failure substantially in all phases of the study.

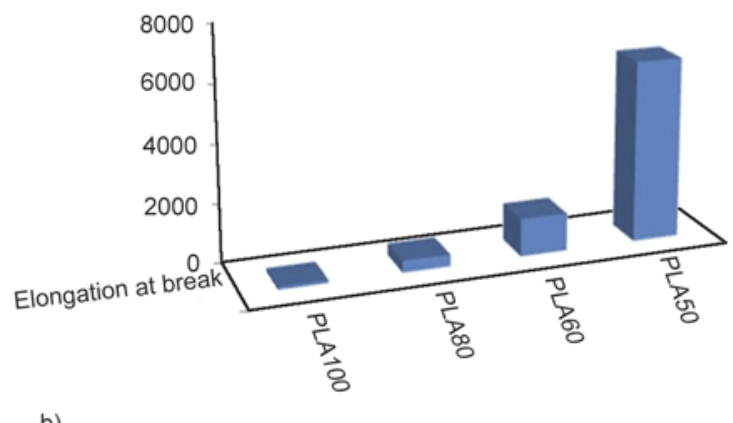

b)

Figure 17. Mechanical and thermal properties of PLA/PTMC blends as a function of PLA content in the blends [75] (a) $T_{\mathrm{g}}$, tensile strength and Young's modulus, (b) elongation at break

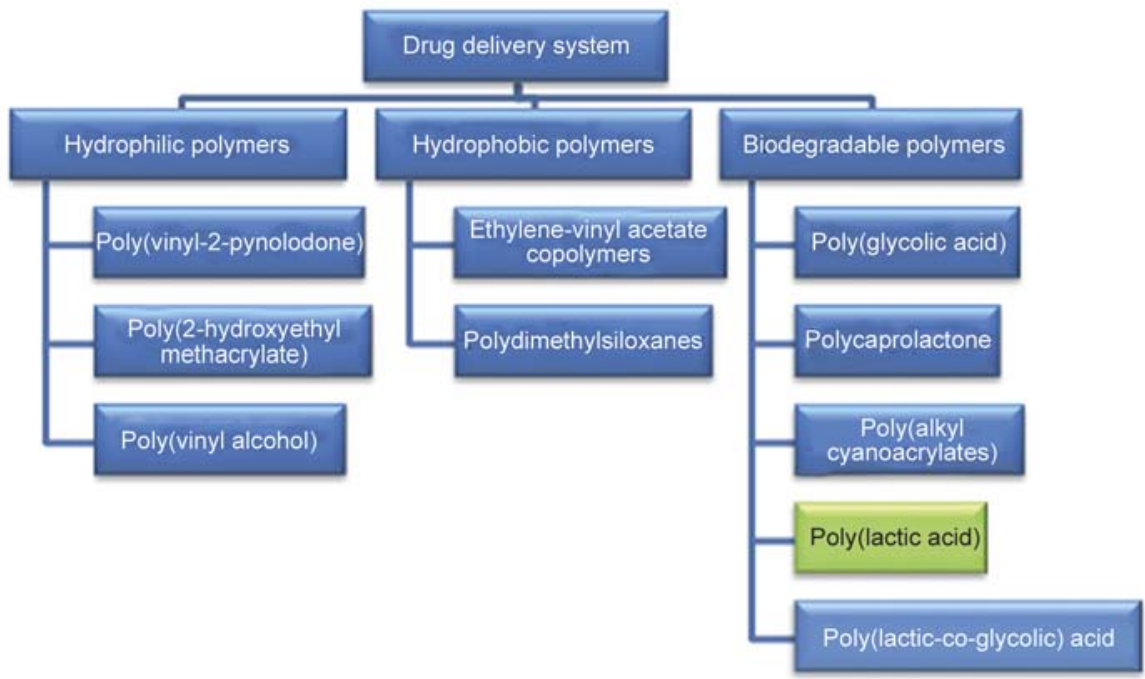

Figure 18. Different types of polymer used in the drug delivery system applications 


\subsection{Drug delivery system}

In drug delivery systems (DDS), the drug could be released continuously for different periods of time up to one year. Different types of polymers including biodegradable polymers were used in this application (Figure 18).

Biodegradable polymers (PLA, PCL, Gelatin, etc.) were used as drug delivery systems owing to their biocompatibility, biodegradability, better encapsulation, and lower toxicity. Polymeric drug release occurred in one of three ways: erosion, diffusion and swelling. In the case of biodegradable polyesters consisting of monomers which were connected to each other by ester bonds, the degradation begun after the penetration of water into the device. The breakage of ester bonds occurred randomly through hydrolytic ester cleavage, leading to subsequent erosion of the device. For degradable polymers, two different erosion mechanisms were proposed: homogeneous or bulk erosion and heterogeneous or surface erosion [79] (Figure 19).

PLA and their copolymers in the form of nano-particles were used in the encapsulation process of many drugs, such as psychotic [80], restenosis [81], hormones [82], oridonin [83], dermatotherapy [84], and protein (BSA) [85]. Different methods were used to obtain these nano-particles, such as solvent evaporation, solvent displacement [86], salting out [80], and emulsion solvent diffusion [87].

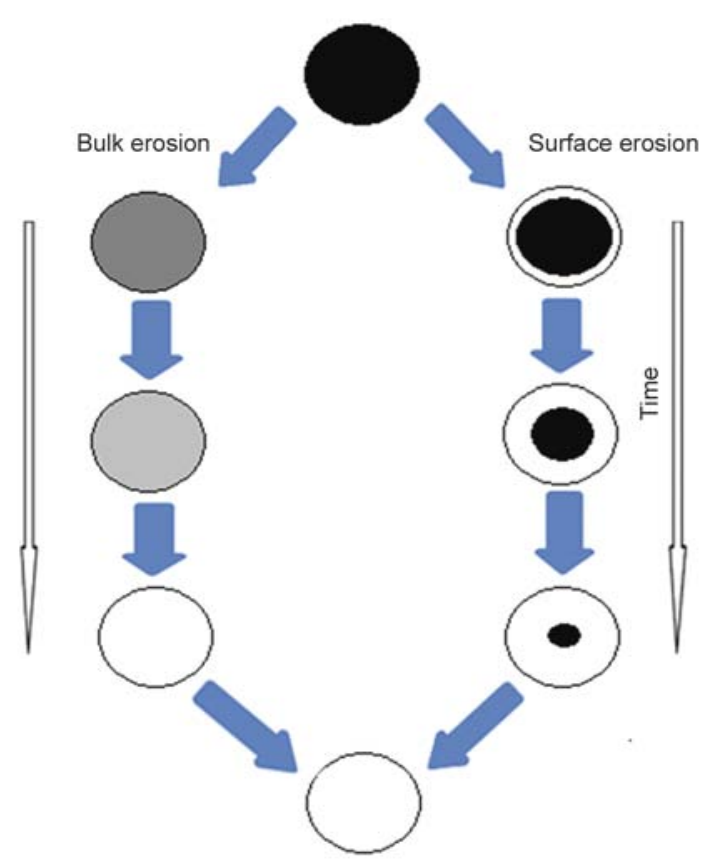

Figure 19. Different erosion mechanisms
Ling and Huang [88] used the poly(lactic-co-glycolic) acid nano-particles for loading the drug, paclitaxel. The nano-particles were prepared using the emulsion solvent evaporation method in the presence of tocopheryl polyethylene glycol succinate as an emulsion agent. The drug loading efficiency, encapsulation efficiency and ability of in vitro drug release of the nano-particles were investigated.

Rancan et al. [84] examined the use of PLA nanoparticles (PLA-NPs) loaded with fluorescent dyes as carriers for transepidermal drug delivery. PLA NPs were prepared using solvent evaporation technology. In this process, PLA was dissolved in acetone, the solution was added to an aqueous solution with moderate stirring and the solvent was then evaporated under reduced pressure at room temperature to obtain the PLA-NPs. The same method was used to obtain the fluorescent particles, where the fluorescent dye and PLA were dissolved in acetone. PLA NPs were tested in human skin. The results showed that PLA NPs could represent ideal candidates for the design of drug delivery systems, which could target active compounds into hair follicles.

\subsection{Orthopedic device}

Biodegradable polymers were used in orthopedic applications to achieve many goals. One of the most important goals was to avoid a second surgical procedure to remove unnecessary hardware (Figure 20). Traditionally, titanium was used in this application, but, in this case, a second surgical procedure was needed to remove the titanium device. Historically, the PLA polymer was used to produce biodegradable screws and fixation pins, plates, and suture anchors. These types of absorbable screws and pins have been gaining the widespread clinical use, particularly in cases where high mechanical stiffness or strength was not required. Pertinent orthopedic areas might include the knee [89-91], shoulder, foot and ankle [92-94], hand, wrist [95], elbow [96], pelvis, and zygomatic fractures. In some cases, high performance PLA was needed, so that techniques would be used to improve the mechanical properties of PLA, particularly impact strength, tensile strength, and flexural strength in fracture fixation, where both metal and biodegradable plate, pins, and rods had limits in their use in fracture fixation.

Haers et al. [97] reported an improvement of the mechanical properties of PLA through the control 


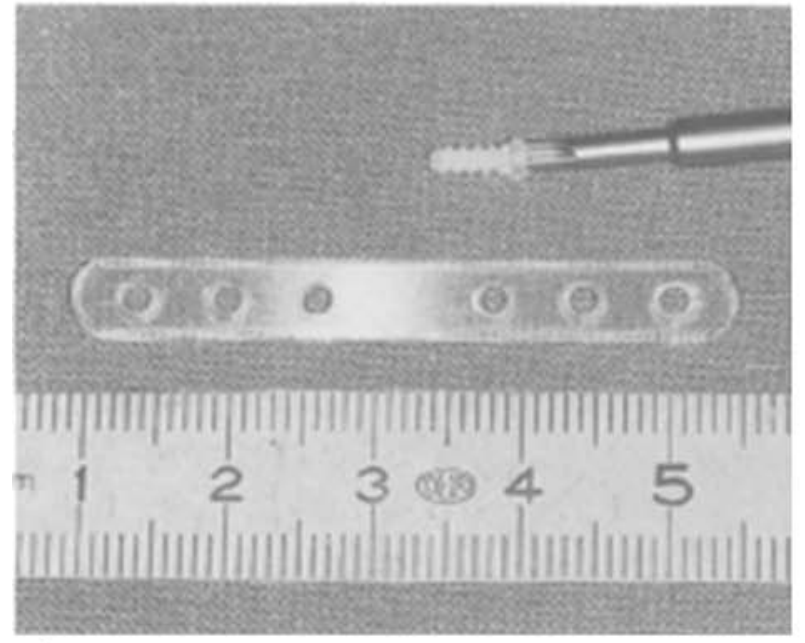

a)

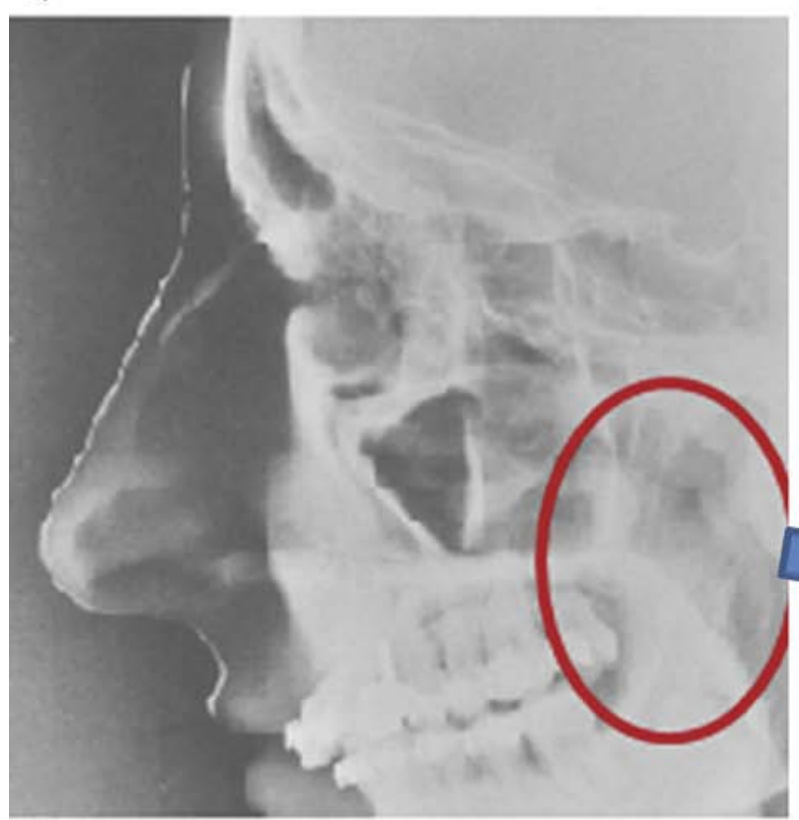

c)

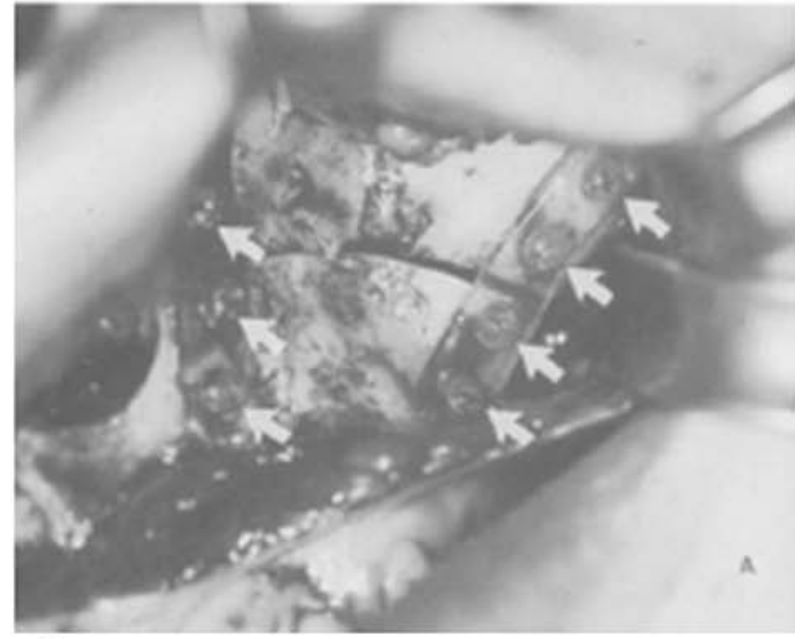

b)

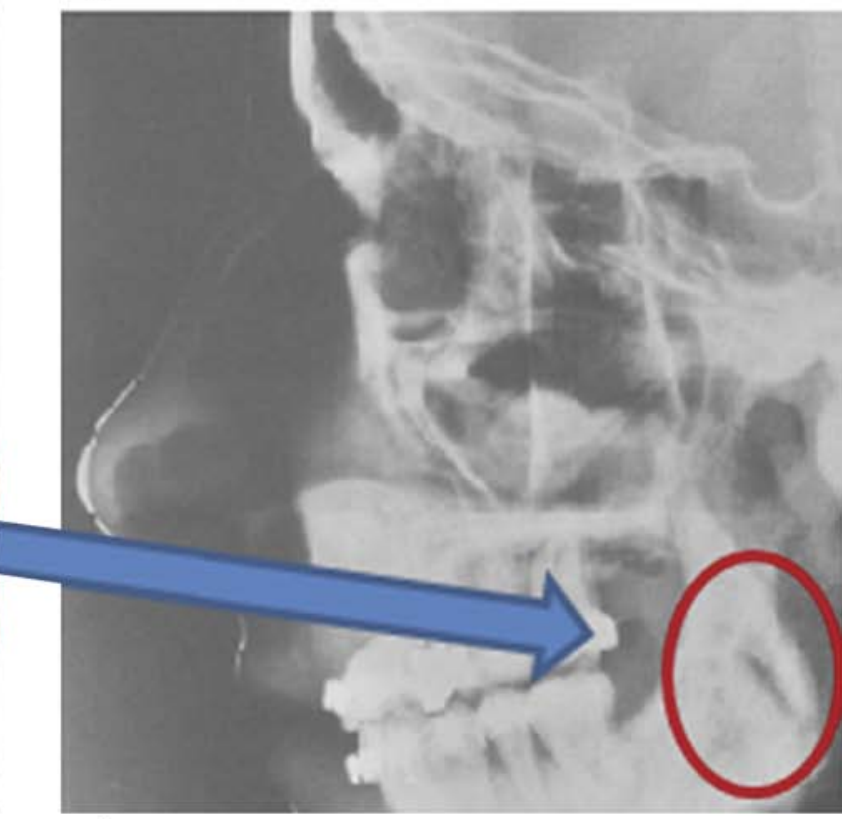

d)

Figure 20. (a) Screws and plate made of PLA (b) upper jaw with the plates and screws in situ (c) and (d) lateral cephalogram, with the screws and plate, taken immediately postoperatively and 6 weeks postoperatively, respectively [97]

of the $L / D$ ratio in the polymer, where the ratio of $L / D$ 85/15 was polymerized, and the prepared PLA was used for the manufacture of screws and fixation plates used in fracture fixation. The results showed that it was possible to use the plates without the need for additional support for the fixation of fractures (Figure 20). van Sliedregt et al. [98] examined the biocompatibility of PLA for orthopedically applications using cell cultures of three types of rat epithelial cells in addition to human fibroblasts and osteosarcoma cells. They found that PLA showed good biocompatibility. Majola et al. [99] reported that PLA rods had good biocompatibility in the cancellous bone of rats. Böstman et al. [92] also reported the biocompatibility of PLA copolymers in the human body. They found that 6 out of 120 patients treated with pins fabricated from a PLA-PGA copolymer developed an aseptic sinus at the implantation site.

\section{Conclusions}

According to the brief review reported in this review paper, the polylactic acid would be one of the promising candidates for various industrial applications. The excellent biocompatibility, low cost, and good materials properties of PLA would open many applications in the medical fields, such as drug delivery systems and orthopedic devices. In addition, the shear thinning behavior of PLA would be suitable for processes using traditional polymer processing technologies, which have also broadened the applications.

More academic attention would be paid to the development of new methods to prepare polylactic acid, 
which would be less expensive and more complex than those of the other polymerization methods. In addition, the development of new applications using PLA in the medical fields would be strongly required for next-generation.

\section{Acknowledgements}

This work was supported by funding from the Yeungnam University Research Project (\#214A367008).

\section{References}

[1] Hamad K., Kaseem M., Ko Y. G., Deri F.: Biodegradable polymer blends and composites: An overview. Polymer Science Series A, 56, 812-829 (2014). DOI: $10.1134 / \mathrm{S} 0965545 X 14060054$

[2] Kaseem M., Hamad K., Deri F.: Thermoplastic starch blends: A review of recent works. Polymer Science Series A, 54, 165-176 (2012). DOI: $10.1134 / \mathrm{S} 0965545 \mathrm{X} 1202006 \mathrm{X}$

[3] Lim L-T., Auras R., Rubino M.: Processing technologies for poly(lactic acid). Progress in Polymer Science, 33, 820-852 (2008).

DOI: $10.1016 /$ j.progpolymsci.2008.05.004

[4] Holten H.: Lactic acid properties and chemistry of lactic acid and derivatives. Verlag Chemie, Weinheim, (1971).

[5] Lunt J.: Large-scale production, properties and commercial applications of polylactic acid polymers. Polymer Degradation and Stability, 59, 145-152 (1998). DOI: 10.1016/S0141-3910(97)00148-1

[6] Lowe E.: Preparation of high molecular weight polyhydroxyacetic ester. U.S. Patent 2668162 A, USA (1954).

[7] Datta R., Henry M.: Lactic acid: Recent advances in products, processes and technologies - A review. Journal of Chemical Technology and Biotechnology, 81, 1119-1129 (2006). DOI: $10.1002 /$ jctb. 1486

[8] Lasprilla A. J. R., Martinez G. A. R., Lunelli B. H., Jardini A. L., Filho R. M.: Poly-lactic acid synthesis for application in biomedical devices - A review. Biotechnology Advances, 30, 321-382 (2012). DOI: $10.1016 /$ j.biotechadv.2011.06.019

[9] Zhang J., Krishnamachari P., Lou J., Shahbazi A.: Synthesis of poly $(\mathrm{L}(+)$ lactic acid) by polycondensation method in solution. in 'Proceedings of the 2007 National Conference on Environmental Science and Technology' (eds.: Nzewi E., Reddy G., Luster-Teasley S., Kabadi V., Chang S-Y., Schimmel K., Uzochukwu G.) Springer, New York 3-8 (2009).

DOI: $10.1007 / 978-0-387-88483-7$

[10] Lei Z., Bai Y., Wang S.: Synthesis of high molecular weight polylactic acid from aqueous lactic acid co-catalyzed by tin(II)chloride dihydrate and succinic anhydride. Chinese Science Bulletin, 50, 2390-2392 (2005). DOI: $10.1360 / 982005-1208$
[11] Achmad F., Yamane K., Quan S., Kokugan T.: Synthesis of polylactic acid by direct polycondensation under vacuum without catalysts, solvents and initiators. Chemical Engineering Journal, 151, 342-350 (2009). DOI: $10.1016 /$ j.cej.2009.04.014

[12] Cheng Y., Deng S., Chen P., Ruan R.: Polylactic acid (PLA) synthesis and modifications: A review. Frontiers of Chemistry in China, 4, 259-264 (2009). DOI: $10.1007 / \mathrm{s} 11458-009-0092-\mathrm{x}$

[13] Auras R., Lim T., Selke M., Tsuji H.: Poly(lactic acid): Synthesis, structures, properties, processing, and applications. Wiley, New Jersey (2010).

[14] Kim E., Shin W., Yoo K., Chung S.: Characteristics of heterogeneous titanium alkoxide catalysts for ringopening polymerization of lactide to produce polylactide. Journal of Molecular Catalysis A: Chemical, 298, 36-39 (2009).

DOI: $10.1016 /$ j.molcata.2008.09.029

[15] Gupta B., Revagade N., Hilborn J.: Poly(lactic acid) fiber: An overview. Progress in Polymer Science, 34, 455-482 (2007).

DOI: $10.1016 /$ j.progpolymsci.2007.01.005

[16] Fang Q., Hanna M.: Rheological properties of amorphous and semicrystalline polylactic acid polymers. Industrial Crops and Products, 10, 47-53 (1999).

DOI: 10.1016/S0926-6690(99)00009-6

[17] Hamad K., Kaseem M., Deri F.: Rheological and mechanical characterization of poly(lactic acid)/polypropylene polymer blends. Journal of Polymer Research, 18, 1799-1806 (2011).

DOI: $10.1007 / \mathrm{s} 10965-011-9586-6$

[18] Hamad K., Kaseem M., Deri F.: Rheological and mechanical properties of poly(lactic acid)/polystyrene polymer blend. Polymer Bulletin, 65, 509-519 (2010). DOI: $10.1007 / \mathrm{s} 00289-010-0354-2$

[19] Hamad K., Kaseem M., Deri F.: Poly(lactic acid)/low density polyethylene polymer blends: Preparation and characterization. Asia-Pacific Journal of Chemical Engineering, 7, 310-316 (2012).

DOI: $10.1002 /$ apj. 1649

[20] Huneault M., Li H.: Morphology and properties of compatibilized polylactide/thermoplastic starch blends. Polymer, 48, 270-280 (2007). DOI: $10.1016 /$ j.polymer.2006.11.023

[21] Shin B., Han D., Narayan R.: Rheological and thermal properties of the PLA modified by electron beam irradiation in the presence of functional monomer. Journal of Polymers and the Environment, 18, 558-566 (2010). DOI: $10.1007 / \mathrm{s} 10924-010-0198-8$

[22] Wang Y., Yang L., Niu Y., Wang Z., Zhang J., Yu F., Zhang H.: Rheological and topological characterizations of electron beam irradiation prepared long-chain branched polylactic acid. Journal of Applied Polymer Science, 122, 1857-1865 (2011). DOI: $\underline{10.1002 / a p p .34276}$ 
[23] Hamad K., Ko Y. G., Kaseem M., Deri F.: Effect of acrylonitrile-butadiene-styrene on flow behavior and mechanical properties of polylactic acid/low density polyethylene blend. Asia-Pacific Journal of Chemical Engineering, 9, 349-353 (2014).

DOI: $10.1002 /$ apj.1802

[24] Saeidlou S., Huneault M. A., Li H., Park C. B.: Poly (lactic acid) crystallization. Progress in Polymer Science, 37, 1657-1677 (2012).

DOI: 10.1016/j.progpolymsci.2012.07.005

[25] Dorgan J. R., Lehermeier H., Mang M.: Thermal and rheological properties of commercial-grade poly(lactic acid)s. Journal of Polymers and the Environment, 8, 1-9 (2000).

DOI: 10.1023/A:1010185910301

[26] Lehermeier H., Dorgan J. R.: Melt rheology of poly (lactic acid): Consequences of blending chain architectures. Polymer Engineering and Science, 41, 21722184 (2001).

DOI: $10.1002 /$ pen.10912

[27] Palade R., Lehermeier H., Dorgan J. R.: Melt rheology of high L-content poly(lactic acid). Macromolecules, 34, 1384-1390 (2001).

DOI: $10.1021 / \mathrm{ma} 001173 \mathrm{~b}$

[28] Liu H., Zhang J.: Research progress in toughening modification of poly(lactic acid). Journal of Polymer Science Part B: Polymer Physics, 49, 1051-1083 (2011).

DOI: $10.1002 /$ polb.22283

[29] Rasal R., Janorkar A., Hirt D.: Poly(lactic acid) modifications. Progress in Polymer Science, 35, 338-356 (2010).

DOI: 10.1016/j.progpolymsci.2009.12.003

[30] Liu G-C., He Y-S., Zeng J-B., Xu Y., Wang Y-Z.: In situ formed crosslinked polyurethane toughened polylactide. Polymer Chemistry, 5, 2530-2539 (2014). DOI: $10.1039 / \mathrm{C} 3 \mathrm{PY} 01649 \mathrm{H}$

[31] Oyama H.: Super-tough poly(lactic acid) materials: Reactive blending with ethylene copolymer. Polymer, 50, 747-751 (2009).

DOI: $10.1016 /$ j.polymer.2008.12.025

[32] Sun S., Zhang M., Zhang H., Zhang X.: Polylactide toughening with epoxy-functionalized grafted acrylonitrile-butadiene-styrene particles. Journal of Applied Polymer Science, 122, 2992-2999 (2011).

DOI: 10.1002/app.34111

[33] Li Y., Shimizu H.: Improvement in toughness of poly (L-lactide) (PLLA) through reactive blending with acrylonitrile-butadiene-styrene copolymer (ABS): Morphology and properties. European Polymer Journal, 45, 738-746 (2009).

DOI: 10.1016/j.eurpolymj.2008.12.010

[34] Hashima K., Nishitsuji S., Inoue T.: Structure-properties of super-tough PLA alloy with excellent heat resistance. Polymer, 51, 3934-3939 (2010).

DOI: $10.1016 /$ j.polymer.2010.06.045
[35] Jo M. Y., Ryu Y. J., Ko J., Yoon J. H., Yoon J-S.: Effects of compatibilizers on the mechanical properties of ABS/PLA composites. Journal of Applied Polymer Science, 125, E231-E238 (2012).

DOI: $10.1002 /$ app.36732

[36] Wang Y., Chiao S., Hung T-F., Yang S-Y.: Improvement in toughness and heat resistance of poly(lactic acid)/polycarbonate blend through twin-screw blending: Influence of compatibilizer type. Journal of Applied Polymer Science, 125, E402-E412 (2012).

DOI: 10.1002/app.36920

[37] Kanzawa T., Tokumitsu K.: Mechanical properties and morphological changes of poly(lactic acid)/polycarbonate/poly(butylene adipate-co-terephthalate) blend through reactive processing. Journal of Applied Polymer Science, 121, 2908-2918 (2011).

DOI: $10.1002 / a p p .33916$

[38] Liu G-C., He Y-S., Zeng J-B., Li Q-T., Wang Y-Z.: Fully biobased and supertough polylactide-based thermoplastic vulcanizates fabricated by peroxide-induced dynamic vulcanization and interfacial compatibilization. Biomacromolecules, 15, 4260-4271 (2014). DOI: $10.1021 / \mathrm{bm} 5012739$

[39] Dorgan J. R., Jansen J., Clayton M. P., Hait S. B., Knauss D. M.: Melt rheology of variable L-content poly(lactic acid). Journal of Rheology, 49, 607-619 (2005). DOI: $10.1122 / 1.1896957$

[40] Liang J-Z., Zhou L., Tang C-Y., Tsui C-P.: Crystalline properties of poly(L-lactic acid) composites filled with nanometer calcium carbonate. Composites Part B: Engineering, 45, 1646-1650 (2013). DOI: $10.1016 /$ j.compositesb.2012.09.086

[41] Hughes J., Thomas R., Byun Y., Whiteside S.: Improved flexibility of thermally stable poly-lactic acid (PLA). Carbohydrate Polymers, 88, 165-172 (2012).

DOI: $10.1016 /$ j.carbpol.2011.11.078

[42] Day M., Nawaby V., Liao X.: A DSC study of the crystallization behaviour of polylactic acid and its nanocomposites. Journal of Thermal Analysis and Calorimetry, 86, 623-629 (2006).

DOI: $10.1007 / \mathrm{s} 10973-006-7717-9$

[43] Yuryev Y., Wood-Adams P. M.: Crystallization of poly(L-/D-lactide) in the presence of electric fields. Macromolecular Chemistry and Physics, 213, 635642 (2012). DOI: $10.1002 / \mathrm{macp} .201100448$

[44] Pyda M., Bopp R. C., Wunderlich B.: Heat capacity of poly(lactic acid). The Journal of Chemical Thermodynamics, 36, 731-742 (2004). DOI: $10.1016 /$ j.jct.2004.05.003

[45] Lee J. K., Lee K. H., Jin B. S.: Structure development and biodegradability of uniaxially stretched poly(Llactide). European Polymer Journal, 37, 907-914 (2001). DOI: 10.1016/S0014-3057(00)00213-5 
[46] Pillin I., Montrelay N., Bourmaud A., Grohens Y.: Effect of thermo-mechanical cycles on the physicochemical properties of poly(lactic acid). Polymer Degradation and Stability, 93, 321-328 (2008).

DOI: $10.1016 /$ j.polymdegradstab.2007.12.005

[47] Żenkiewicz M., Richert J., Rytlewski P., Moraczewski K., Stepczyńska M., Karasiewicz T.: Characterisation of multi-extruded poly(lactic acid). Polymer Testing, 128, 412-418 (2009).

DOI: 10.1016/j.polymertesting.2009.01.012

[48] Al-Itry R., Lamnawar K., Maazouz A.: Improvement of thermal stability, rheological and mechanical properties of PLA, PBAT and their blends by reactive extrusion with functionalized epoxy. Polymer Degradation and Stability, 97, 1898-1914 (2012).

DOI: $10.1016 /$ j.polymdegradstab.2012.06.028

[49] Hamad K., Kaseem M., Deri F.: Effect of recycling on rheological and mechanical properties of poly(lactic acid)/polystyrene polymer blend. Journal of Materials Science, 46, 3013-3019 (2011).

DOI: $10.1007 / \mathrm{s} 10853-010-5179-8$

[50] Auras R., Harte B., Selke S.: Effect of water on the oxygen barrier properties of poly(ethylene terephthalate) and polylactide films. Journal of Applied Polymer Science, 92, 1790-1803 (2004).

DOI: $10.1002 / a p p .20148$

[51] Auras R. A., Singh S. P., Singh J. J.: Evaluation of oriented poly(lactide) polymers vs. existing PET and oriented PS for fresh food service containers. Packaging Technology and Science, 18, 207-216 (2005).

DOI: $10.1002 /$ pts. 692

[52] Thellen C., Orroth C., Froio D., Ziegler D., Lucciarini J., Farrell R., D’Souza N. A., Ratto J. A.: Influence of montmorillonite layered silicate on plasticized poly(Llactide) blown films. Polymer, 46, 11716-11727 (2005). DOI: 10.1016/j.polymer.2005.09.057

[53] Chaiwong C., Rachtanapun P., Wongchaiya P., Auras R., Boonyawan D.: Effect of plasma treatment on hydrophobicity and barrier property of polylactic acid. Surface and Coatings Technology, 204, 2933-2939 (2010).

DOI: $10.1016 /$ j.surfcoat.2010.02.048

[54] Jamshidian M., Tehrany E., Cleymand F., Leconte S., Falher T., Desobry S.: Effects of synthetic phenolic antioxidants on physical, structural, mechanical and barrier properties of poly lactic acid film. Carbohydrate Polymers, 87, 1763-1773 (2012).

DOI: $10.1016 /$ j.carbpol.2011.09.089

[55] Bao L., Dorgan J. R., Knauss D., Hait S., Oliveira N. S., Maruccho I. M.: Gas permeation properties of poly (lactic acid) revisited. Journal of Membrane Science, 285, 166-172 (2006).

DOI: $10.1016 /$ j.memsci.2006.08.021

[56] Al-Mulla E. A. J., Yunus W. M. Z. W., Ibrahim N. A. B., Rahman M. Z. A.: Properties of epoxidized palm oil plasticized polytlactic acid. Journal of Materials Science, 45, 1942-1946 (2010).

DOI: $10.1007 / \mathrm{s} 10853-009-4185-1$
[57] Martino V. P., Jiménez A., Ruseckaite R. A.: Processing and characterization of poly(lactic acid) films plasticized with commercial adipates. Journal of Applied Polymer Science, 112, 2010-2018 (2009).

DOI: 10.1002/app.29784

[58] NatureWorks LLC: Sheet extrusion processing guide. Minnetonka (2005).

[59] Carrasco F., Cailloux J., Sánchez-Jiménez P. E., Maspoch M. L. I.: Improvement of the thermal stability of branched poly(lactic acid) obtained by reactive extrusion. Polymer Degradation and Stability, 104, 40-49 (2014).

DOI: $10.1016 /$ j.polymdegradstab.2014.03.026

[60] Sato Y., Inohara K., Takishima S., Masuoka H., Imaizumi M., Yamamoto H., Takasugi M.: Pressurevolume-temperature behavior of polylactide, poly(butylene succinate), and poly(butylene succinate-co-adipate). Polymer Engineering and Science, 40, 26022609 (2000).

DOI: $10.1002 /$ pen. 11390

[61] Kale G., Auras R., Singh P.: Comparison of the degradability of poly(lactide) packages in composting and ambient exposure conditions. Packaging Technology and Science, 20, 49-70 (2007).

DOI: $10.1002 /$ pts. 742

[62] Kale G., Auras R., Singh S. P.: Degradation of commercial biodegradable packages under real composting and ambient exposure conditions. Journal of Polymers and the Environment, 14, 317-334 (2006).

DOI: $10.1007 / \mathrm{s} 10924-006-0015-6$

[63] Weng Y-X., Jin Y-J., Meng Q-Y., Wang L., Zhang M., Wang Y-Z.: Biodegradation behavior of poly(butylene adipate-co-terephthalate) (PBAT), poly(lactic acid) (PLA), and their blend under soil conditions. Polymer Testing, 32, 918-926 (2013).

DOI: $10.1016 /$ j.polymertesting.2013.05.001

[64] Kale G., Auras R., Singh S. P., Narayan R.: Biodegradability of polylactide bottles in real and simulated composting conditions. Polymer Testing, 26, 1049-1061 (2007).

DOI: $10.1016 / j$.polymertesting.2007.07.006

[65] Kale G., Kijchavengkul T., Auras R., Rubino M., Selke S. E., Singh S. P.: Compostability of bioplastic packaging materials: An overview. Macromolecular Bioscience, 7, 255-277 (2007).

DOI: 10.1002/mabi.200600168

[66] Ohkita T., Lee S-H.: Thermal degradation and biodegradability of poly (lactic acid)/corn starch biocomposites. Journal of Applied Polymer Science, 100, 3009-3017 (2006).

DOI: 10.1002/app.23425

[67] Bain J. R.: Peripheral nerve allografting: Review of the literature with relevance to composite tissue transplantation. Transplantation Proceedings, 30, 27622767 (1998).

DOI: $10.1016 / \mathrm{S} 0041-1345(98) 00804-5$ 
[68] Langer R., Vacanti P.: Tissue engineering. Science, 260, 920-926 (1993).

DOI: $10.1126 /$ science.8493529

[69] Mitragotri S., Lahann J.: Physical approaches to biomaterial design. Nature Materials, 8, 15-23 (2009). DOI: $10.1038 /$ nmat2344

[70] Zhang Q., Mochalin V. N., Neitzel I., Knoke I. Y., Han J., Klug C. A., Zhou J. G., Lelkes P. I., Gogotsi Y.: Fluorescent PLLA-nanodiamond composites for bone tissue engineering. Biomaterials, 32, 87-94 (2011). DOI: $10.1016 /$ j.biomaterials.2010.08.090

[71] Saito N., Takaoka K.: New synthetic biodegradable polymers as BMP carriers for bone tissue engineering. Biomaterials, 24, 2287-2293 (2003).

DOI: 10.1016/S0142-9612(03)00040-1

[72] Murakami N., Saito N., Horiuchi H., Okada T., Nozaki K., Takaoka K.: Repair of segmental defects in rabbit humeri with titanium fiber mesh cylinders containing recombinant human bone morphogenetic protein-2 (rhBMP-2) and a synthetic polymer. Journal of Biomedical Materials Research Part A, 62, 169-174 (2002).

DOI: $10.1002 / \mathrm{jbm} .10236$

[73] Chang P-C., Liu B-Y., Liu C-M., Chou H-H., Ho MH., Liu L-C., Wang D-M., Hou L-T.: Bone tissue engineering with novel rhBMP2-PLLA composite scaffolds. Journal of Biomedical Materials Research Part A, 81, 771-780 (2007).

DOI: $10.1002 / \mathrm{jbm} . \mathrm{a} .31031$

[74] Li G., Wang Z-X., Fu W-J., Hong B-F., Wang X-X., Cao L., Xu F-Q., Song Q., Cui F-Z., Zhang X.: Introduction to biodegradable polylactic acid ureteral stent application for treatment of ureteral war injury. BJU International, 108, 901-906 (2011).

DOI: 10.1111/j.1464-410X.2010.09992.X

[75] Qin Y., Yuan M., Li L., Guo S., Yuan M., Li W., Xue J.: Use of polylactic acid/polytrimethylene carbonate blends membrane to prevent postoperative adhesions. Journal of Biomedical Materials Research Part B: Applied Biomaterials, 79, 312-319 (2006). DOI: $10.1002 / \mathrm{jbm} . b .30544$

[76] Bhatia A., Gupta R. K., Bhattacharya S. N., Choi H. J.: Compatibility of biodegradable poly (lactic acid) (PLA) and poly (butylene succinate) (PBS) blends for packaging application. Korea-Australia Rheology Journal, 19, 125-131 (2007).

[77] Fraisse F., Verney V., Commereuc S., Obadal M.: Recycling of poly(ethylene terephthalate)/polycarbonate blends. Polymer Degradation and Stability, 90, 250 255 (2005).

DOI: 10.1016/j.polymdegradstab.2005.02.019

[78] Brekke J. H., Olson R. A. J., Scully J. R., Osbon D. B.: Influence of polylactic acid mesh on the incidence of localized osteitis. Oral Surgery, Oral Medicine, Oral Pathology, 56, 240-245 (1983). DOI: $10.1016 / 0030-4220(83) 90003-8$
[79] Kumari A., Yadav S. K., Yadav S. C.: Biodegradable polymeric nanoparticles based drug delivery systems. Colloids and Surfaces B: Biointerfaces, 75, 1-18 (2010). DOI: $10.1016 /$ j.colsurfb.2009.09.001

[80] Leroux J-C., Allémann E., De Jaeghere F., Doelker E., Gurny R.: Biodegradable nanoparticles - From sustained release formulations to improved site specific drug delivery. Journal of Controlled Release, 39, 339350 (1996).

DOI: 10.1016/0168-3659(95)00164-6

[81] Fishbein I., Chorny M., Rabinovich L., Banai S., Gati I., Golomb G.: Nanoparticulate delivery system of a tyrphostin for the treatment of restenosis. Journal of Controlled Release, 65, 221-229 (2000). DOI: $10.1016 / \mathrm{S} 0168-3659(99) 00244-8$

[82] Matsumoto J., Nakada Y., Sakurai K., Nakamura T., Takahashi Y.: Preparation of nanoparticles consisted of poly(L-lactide)-poly(ethylene glycol)-poly(L-lactide) and their evaluation in vitro. International Journal of Pharmacy, 185, 93-101 (1999).

DOI: $10.1016 / \mathrm{S} 0378-5173(99) 00153-2$

[83] Xing J., Zhang D., Tan T.: Studies on the oridoninloaded poly(D,L-lactic acid) nanoparticles in vitro and in vivo. International Journal of Biological Macromolecules, 40, 153-158 (2007).

DOI: 10.1016/j.ijbiomac.2006.07.001

[84] Rancan F., Papakostas D., Hadam S., Hackbarth S., Delair T., Primard C., Verrier B., Sterry W., BlumePeytavi U., Vogt A.: Investigation of polylactic acid (PLA) nanoparticles as drug delivery systems for local dermatotherapy. Pharmaceutical Research, 26, 20272036 (2009).

DOI: $10.1007 / \mathrm{s} 11095-009-9919-\mathrm{x}$

[85] Gao H., Wang Y. N., Fan Y. G., Ma J. B.: Synthesis of a biodegradable tadpole-shaped polymer via the coupling reaction of polylactide onto mono(6-(2-aminoethyl)amino-6-deoxy)- $\beta$-cyclodextrin and its properties as the new carrier of protein delivery system. Journal of Controlled Release, 107, 158-173 (2005). DOI: $10.1016 /$ j.jconrel.2005.06.010

[86] Fessi H., Puisieux F., Devissaguet J. P., Ammoury N., Benita S.: Nanocapsule formation by interfacial polymer deposition following solvent displacement. International Journal of Pharmaceutics, 55, R1-R4 (1989). DOI: 10.1016/0378-5173(89)90281-0

[87] Esmaeili F., Ghahremani M. H., Ostad S. N., Atyabi F., Seyedabadi M., Malekshahi M. R., Amini M., Dinarvand R.: Folate-receptor-targeted delivery of docetaxel nanoparticles prepared by PLGA-PEG-folate conjugate. Journal of Drug Targeting, 16, 415-423 (2008). DOI: $10.1080 / 10611860802088630$

[88] Ling Y., Huang Y.: Preparation and release efficiency of poly (lactic-co-glycolic) acid nanoparticles for drug loaded paclitaxel. IFMBE Proceedings, 19, 514-517 (2008).

DOI: $10.1007 / 978-3-540-79039-6129$ 
[89] Barber F. A., Elrod B. F., McGuire D. A., Paulos L. E.: Preliminary results of an absorbable interference screw. Arthroscopy: The Journal of Arthroscopic and Related Surgery, 11, 537-548 (1995). DOI: 10.1016/0749-8063(95)90129-9

[90] Matsusue Y., Nakamura T., Suzki S., Iwasaki R.: Biodegradable pin fixation of osteochondral fragments of the knee. Clinical Orthopaedics and Related Research, 322, 166-173 (1996).

[91] Stähelin A. C., Weiler A., Rüfenacht H., Hoffmann R., Geissmann A., Feinstein R.: Clinical degradation and biocompatibility of different bioabsorbable interference screws: A report of six cases. Arthroscopy: The Journal of Arthroscopic and Related Surgery, 13, 238244 (1997).

DOI: $10.1016 / \mathrm{S} 0749-8063(97) 90162-6$

[92] Böstman O., Hirvensalo E., Vainionpää S., Mäkelä A., Vihtonen K., Törmälä P., Rokkanen P.: Ankle fractures treated using biodegradable internal fixation. Clinical Orthopaedics and related research, 238, 195-203 (1989).

[93] Lavery A., Higgins K. R., Ashry H. R., Athanasiou K. A.: Mechanical characteristics of poly-L-lactic acid absorbable screws and stainless steel screws in basilar osteotomies of the first metatarsal. Journal of Foot Ankle Surgery, 33, 249-254 (1994).

[94] Bucholz R. W., Henry S., Henley M. B.: Fixation with bioabsorbable screws for the treatment of fractures of the ankle. Journal of Bone and Joint Surgery, 76, 319 324 (1994).
[95] Casteleyn P. P., Handelberg F., Haentjens P.: Biodegradable rods versus Kirschner wire fixation of wrist fractures. A randomised trial. Journal Bone and Joint Surgery, 74, 858-861 (1992).

[96] Hope P. G., Williamson D. M., Coates C. J., Cole W. G.: Biodegradable pin fixation of elbow fractures in children: A randomized trial. Journal Bone and Joint Surgery, 73, 965-968 (1991).

[97] Haers P. E., Suuronen R., Lindqvist C., Sailer H.: Biodegradable polylactide plates and screws in orthognathic surgery: Technical note. Journal of CranioMaxillofacial Surgery, 26, 87-91 (1998). DOI: $10.1016 / \mathrm{S} 1010-5182(98) 80045-0$

[98] van Sliedregt A., Radder A. M., de Groot K., van Blitterswijk C. A.: In vitro biocompatibility testing of polylactides Part I Proliferation of different cell types. Journal of Materials Science: Materials in Medicine, 3, 365-370 (1992).

DOI: $10.1007 / \mathrm{BF} 00705369$

[99] Majola A., Vainionpää S., Vihtonen K., Mero M., Vasenius J., Törmälä P., Rokkanen P.: Absorption, biocompatibility, and fixation properties of polylactic acid in bone tissue: An experimental study in rats. Clinical Orthopaedics and Related Research, 268, 260-269 (1991). 